\title{
Challenges and Opportunities of Carbon Nanomaterials for Biofuel Cells and Supercapacitors: Personalized Energy for Futuristic Self-Sustainable Devices
}

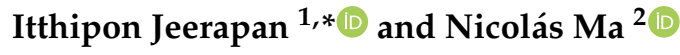 \\ 1 Department of Chemistry, Faculty of Science, Prince of Songkla University, Hat Yai, Songkla 90112, Thailand \\ 2 Department of Bioengineering, University of California San Diego, La Jolla, CA 92093, USA; nma@ucsd.edu \\ * Correspondence: itthipon.j@psu.ac.th
}

Received: 8 September 2019; Accepted: 5 October 2019; Published: 9 October 2019

check for updates

\begin{abstract}
Various carbon allotropes are fundamental components in electrochemical energy-conversion and energy-storage devices, e.g., biofuel cells (BFCs) and supercapacitors. Recently, biodevices, particularly wearable and implantable devices, are of distinct interest in biomedical, fitness, academic, and industrial fields due to their new fascinating capabilities for personalized applications. However, all biodevices require a sustainable source of energy, bringing widespread attention to energy research. In this review, we detail the progress in BFCs and supercapacitors attributed to carbon materials. Self-powered biosensors for futuristic biomedical applications are also featured. To develop these energy devices, many challenges needed to be addressed. For this reason, there is a need to: optimize the electron transfer between the enzymatic site and electrode; enhance the power efficiency of the device in fluctuating oxygen conditions; strengthen the efficacy of enzymatic reactions at the carbon-based electrodes; increase the electrochemically accessible surface area of the porous electrode materials; and refine the flexibility of traditional devices by introducing a mechanical resiliency of electrochemical devices to withstand daily multiplexed movements. This article will also feature carbon nanomaterial research alongside opportunities to enhance energy technology and address the challenges facing the field of personalized applications. Carbon-based energy devices have proved to be sustainable and compatible energy alternatives for biodevices within the human body, serving as attractive options for further developing diverse domains, including individual biomedical applications.
\end{abstract}

Keywords: carbon nanomaterials; biofuel cells; supercapacitors; self-powered sensors; wearable technology; stretchable devices; enzymes; oxygen; personalized biomedical energy devices

\section{Introduction}

With the increasing development of electronic and bioelectronic technologies, electrical energy conversion and storage are recognized as crucial divisions. Carbon materials have opened up new opportunities for efficient energy conversion and storage, particularly biofuel cells (BFCs) and supercapacitors. Carbon and its various allotropes have been the lifeblood of these technologies, in the sense that their chemical and electronic properties have long been explored for expediting these developments [1,2]. From their use as a benign high-surface area and electronically conductive support for electrochemical energy devices to their role in revolutionizing BFC and supercapacitor technologies, special attention must be given to certain carbon developments. Some of these include nanostructured carbon-supports and tailored surface chemistry carbon materials (particularly CNTs and graphene) as energy materials. These advancements possess unique properties useful for enhancing 
energy-conversion (i.e., BFCs) and energy-storage (i.e., supercapacitors) performances. More recent use of carbon for energy applications can be seen in technologies for personalized use, such as miniaturized, portable, wearable, or implantable applications. Electrodes with carbon materials and their composites functionalized for charge collection are highly attractive for use in personalized energy-harvesting technologies due to their outstanding electrochemical properties, electrical conductivity, and flexibility. In addition, carbonaceous nanomaterials have been applied to establish bionano interfaces, in order to optimize electron-transfer processes in BFCs that require competent electrochemical communication between enzymes and carbon nanomaterials. This makes carbon materials an attractive option for the future development of flexible, stretchable, and personalized energy electronics. By paying proper attention to key obstacles and leveraging the advantages of carbon materials, these innovations could have a tremendous impact on electrochemical energy-related applications.

Personalized electronics (particularly, wearables and implantables) play a significant role in many fields in the modern age. Emerging electronic devices (e.g., wearables) are not only relegated to entertainment but provide features such as biosensing capabilities [3,4], which have been garnering substantial attention in both industrial and academic fields because of their increasingly viable applications. These also include biomedical devices [5,6], artificial skin [7], and soft robotics [8] incorporating arbitrarily shaped surfaces. Further examples of wearable applications extend to biosensors, where the sensors can ideally interact and communicate with their environment. The personalized electronic field benefits from the advent of these devices, being able to incorporate flexible circuits, conformable and flexible displays, electronic paper, touch screens, and skin-like sensing capabilities into data collection and large-scale healthcare. Personalized electronics have quickly crossed into digital health territory in various biomedical applications [9], including tracking the various vital signs of wearers with the intention of improving their community's healthcare. In addition to biomedical implantable devices, some of these technologies have become part of our contemporary lives in the form of wearable accessories such as smartwatches, armbands, and glasses. Therefore, the ever-growing demand for developing effective personalized energy devices is at an all-time high to power said biomedical electronics. In order to ensure the sustainability of the bioelectronic system, the corresponding personalized power sources must deliver a stable and persistent electricity output. These devices should maintain satisfactory performances under real conditions and in real scenarios such as biocompatibility, small size, light, stretchability, and mechanical resiliency.

This article reviews the progress of innovative supercapacitors and BFCs that have been developed toward personalized applications. Supercapacitors have recently been brought to the forefront of energy-source alternatives for individual applications due to their fast charge/discharge capacity, long cycle life, and safety $[10,11]$. These energy-storage devices are required for powering any desired electronics. As a result, supercapacitors play a vital role in biomedical and personalized applications, overcoming the limitation of needing a constant supply of energy. In addition to supercapacitors that can store energy, energy-harvesting devices can also incorporate conformal supercapacitors to store the generated energy. This energy can then be utilized to power a variety of personalized devices, such as wearable sensors [12]. BFCs represent another important category, i.e., energy-harvesting devices, in particular, for personal and biomedical applications $[4,13,14]$. BFCs, which convert biochemical energy into electrical energy using the assistance of biological components (in particular, enzymes), provide an emerging "green" alternative for numerous wearable and implantable applications. Biofluids, such as sweat [15], tears [16], interstitial fluid [17], and blood [18], contain useful metabolites, such as glucose and lactate, that can be used as fuel for personalized BFCs to generate electrical energy. Interestingly, BFCs can also be designed to act as efficient, self-powered sensors, allowing these systems to mandate lower energy requirements as compared to conventional electrochemical sensors.

Although researchers are continuing to develop new energy devices based on a variety of carbon materials, there is a continuing need to improve these applications. Revolutionizing traditional carbon electrodes toward personalized application requires careful engineering to address several key limitations (Figure 1), which will be discussed in our review. Many of these challenges include 
concepts relating to bio/nanoengineering, electrochemistry, and material science. For example, optimizing the electron transfer between the reactive site and carbon electrode requires different electrical wiring techniques, which is a primary impact on the enhancement of biocatalytic BFCs. Oxygen also holds a strong role in the cathode compartment in BFCs. This leads to a predicament where oxygen is needed to enhance the power efficiency, while accounting for fluctuating oxygen conditions to improve the oxygen reduction of the cathode. Moreover, another issue is developing strategies to improve the efficacy of the biofuel consumption at the enzymatic active site, which can be achieved by stabilizing the enzymes, biocatalytic activity, and active materials within the carbon electrode. Another requirement is to optimize the surface area of the electrode at electrochemically accessible locations by carefully engineering the architecture and porosity of the carbon-based materials. Furthermore, for bio-integrations with the curvature of the human body, such as for wearable and implantable applications, there is a challenge to improve on the flexibility of traditional energy biodevices. The devices must incorporate mechanical resiliency while maintaining good electrochemical functionalities of carbon-based devices. More attention to these types of challenges, which will be detailed in this article, will have a major positive impact in the wearable technology and other personalized energy-related bioelectronics.

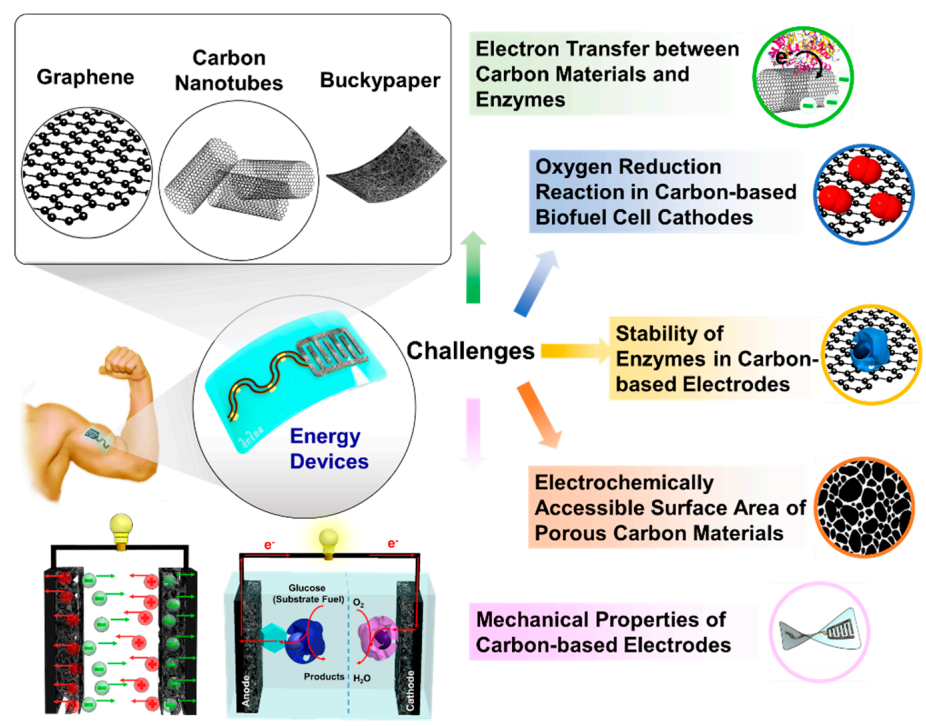

Figure 1. (Left) Illustration of the applications of carbon nanomaterials and composites for electrochemical energy devices. (Right) Examples of challenges in the development of carbon-based supercapacitors and BFCs toward personalized applications, such as wearable and implantable purposes.

This perspective review aims to cover the progress made in emerging personalized BFCs and supercapacitors that have utilized carbon materials. First, we provide a detailed overview of the principles and material aspects of the components in energy related devices; including supercapacitors, BFCs, and innovative self-powered biosensing devices. We summarize the progress of reported developments in energy devices, which are based on carbon nanomaterials. As well as discussing important achievements in the field of personalized carbon-based energy devices, we also illustrate the challenges that currently hinder further developments. This article focuses on presenting examples of carbon-based energy systems to address key challenges in the field. The comprehensive and fundamental information regarding the preparation and properties of various types of carbon materials, not fully included in the sections of this review, can be viewed in published reports [19-24]. Finally, we discuss the future perspectives and remaining challenges toward the practical application of personalized, miniaturized, and/or conformal supercapacitors, BFCs, and self-powered biosensing devices with reliable mechanical functionality and stable electrochemical 
performance. This application occurs under the strain of repeated personal use, such as modern digital health and other practical energy-requiring biomedical applications (i.e., biosensing/diagnosing and therapeutic management). In addition to personal applications, advancements in carbon research toward energy applications will greatly impact various domains of high-performing energy device developments with special characteristics.

\section{Moving Supercapacitors toward Personalized Platforms}

A supercapacitor is comprised of electrodes, electrolytes, and usually a separator (separating the positive and negative electrodes) as shown in Figure 2 [25,26]. Mechanisms of supercapacitors can be classified into two main categories: an electrostatic process (double-layer capacitors) and an electrochemical process (pseudocapacitors). In addition, hybrid capacitors can also combine both electrostatic and electrochemical processes. The electrode materials, particularly carbon-based materials, are significant toward the storage performance of supercapacitors $[27,28]$. For instance, double-layer capacitors employ activated carbon, graphene, and CNTs. Pseudocapacitors use conductive carbon-based composites, integrated with conducting polymers [29,30], metal oxides [31,32], and metal sulfides [33,34].

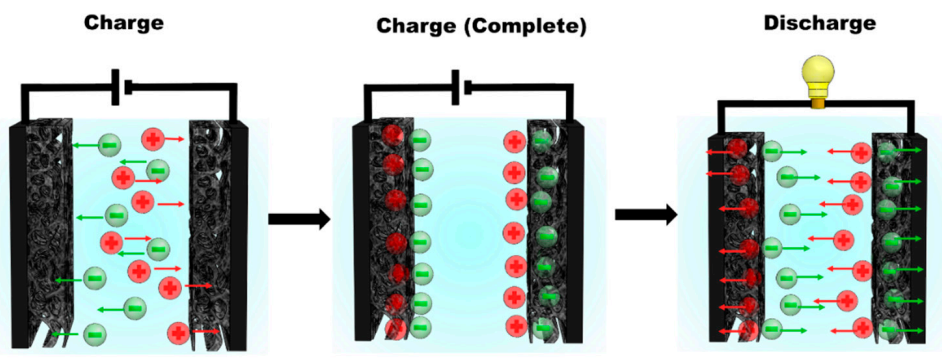

Figure 2. The charging/discharging cycles of a carbon-based supercapacitor.

Carbon electrode materials serve as major contributors toward the performance of the supercapacitor. Carbon materials, such as activated carbon, carbon aerogels, CNTs, and graphene help exhibit the electric double-layer capacitors (EDLC) [35-37]. In general, these carbon-based materials alone are electrochemically inert, and the energy storage only takes place due to the accumulation of the charges/ions on the electrode surface. The carbon or composite material-coated electrodes can act as active materials and/or collectors. In principle, as shown in Figure 2, carbon-based supercapacitors contain an electrical double layer formed at each carbon interface where the carbon material is in contact with the electrolyte. When the supercapacitor is charging, the negative ions and vacancies on the cathode, and the positive ions and the electrons on the anode are arranged across the interface. This arrangement of ions and electrons (vacancies) during the charged state is known as an "electrical double layer". Since the layer is composed of multiple ions moving, there is no major chemical reaction involved such as in conventional batteries. This yields a superior charge-discharge life cycle. Porous carbon is used on the electrode to increase its surface area [37]. The greater the surface area, the greater the charge that can be stored; therefore, the supercapacitor with highly porous carbon nanomaterials is able to reach a higher capacitance. More comprehensive reviews, including an overview of electrochemical performances in energy-related applications of carbon-based materials, can be found further in earlier publications $[23,24,38-40]$.

Cellular graphene, providing high electrical conductivity, a large surface area, and fully interconnected porous geometry, has attracted widespread interest as a support for complex three-dimensional (3D) graphene hierarchical architectures. However, some limitations inhibit the potential of this carbon material as a building block for larger applications. Because of their irregularly distributed porous microstructures, cellular graphene maintains a low stretchability, proving to be a drawback for personal applications. The material's electrochemical performance is also dramatically affected by mechanical deformations under moderate levels of strain, limiting its 
viability in emerging wearable energy devices. In order to overcome these challenges, a mechanically guided 3D assembly approach must be taken to both control the cellular graphene architecture's physical structure and achieve the desired geometry (Figure 3A) [41]. The approach would exploit stress release in pre-strained elastomer substrates in order to drive predesigned two-dimensional (2D) patterns to eventually transform geometrically into 3D architectures. When the applied device is biaxially stretched to $100 \%$, the change in areal capacitance is negligible in the 3D supercapacitors. This is exemplified when after 100\% cyclic stretching occurred 1000 times, the areal capacitance only changed $9 \%$.

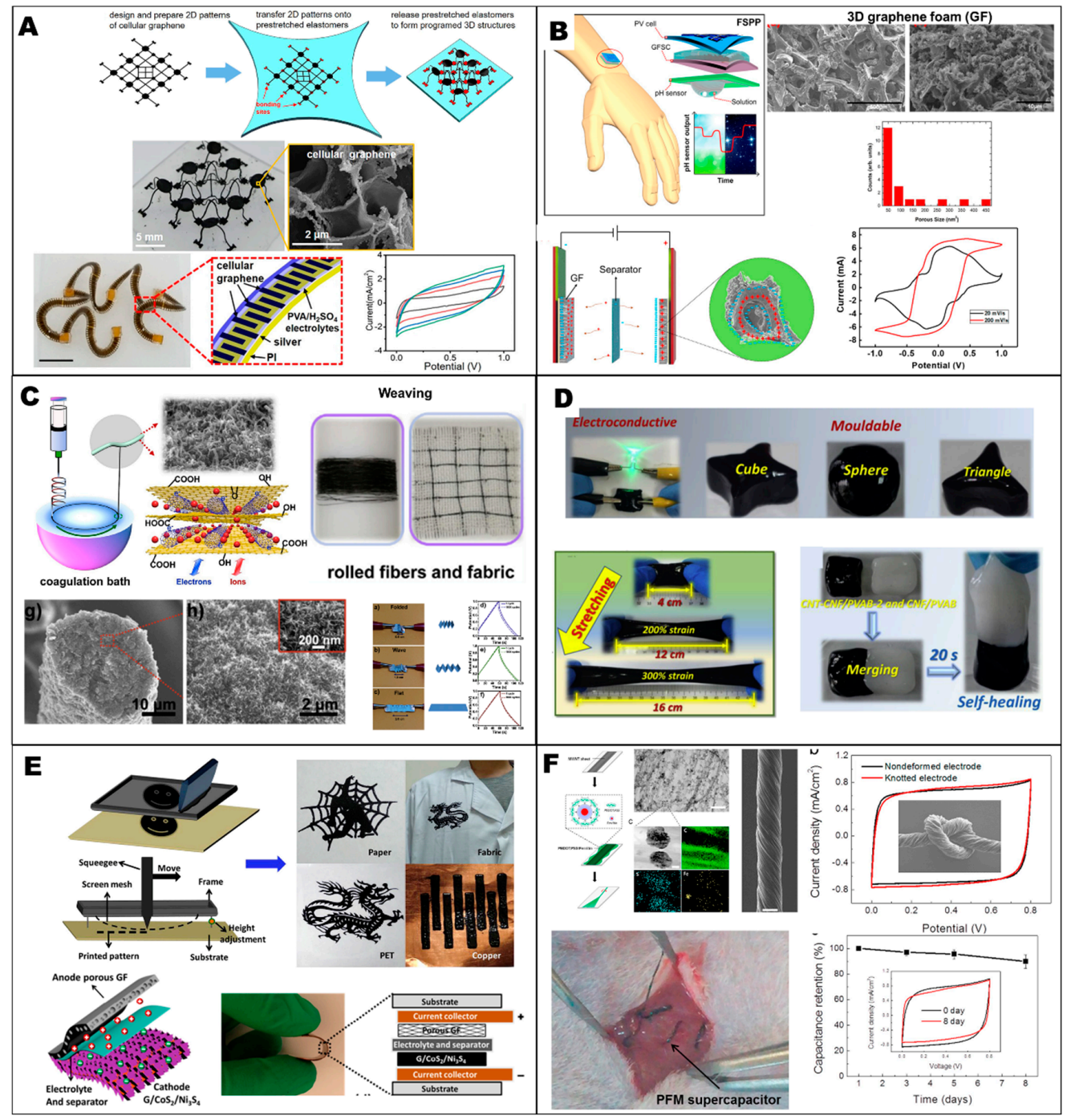

Figure 3. Examples of applications of carbon materials for supercapacitors and potential opportunities toward the development of personalized energy storage. (A) Mechanically assembled, three-dimensional (3D) structures of cellular graphene with programmed geometries. Adapted with permission from [41], Copyright 2018, American Chemical Society. (B) Graphene-Ag-3D graphene foam for a flexible self-charging supercapacitor. Adapted with permission from [42], Copyright 2018, Elsevier. (C) Reduced graphene oxide/CNT fibers with mesopores for flexible supercapacitors. Adapted with permission from [43], Copyright 2019, Elsevier. (D) Nanocellulose-templated CNTs embedded in a polymer network for self-healable and flexible supercapacitors. Adapted with permission from [44], Copyright 2019, Elsevier. (E) Screen-printable films of graphene/metal sulfides for flexible and arbitrary-shaped all-solid-state supercapacitors. Adapted with permission from [34], Copyright 2019, Elsevier. (F) CNT-based fiber supercapacitor for implantable devices. Adapted with permission from [45], Copyright 2018, Elsevier. 
An example of a specially designed, foam-based 3D supercapacitor made up of porous graphene exhibited excellent electrochemical and supercapacitive performance (Figure 3B) [42]. The special structure was layered with highly conductive electrodes, made from graphene-Ag conductive epoxy-graphene foam, forming an electrochemical double layer. The electrode was matched with the electrolyte $\mathrm{H}_{3} \mathrm{PO}_{4}$, where it yielded an areal capacitance of $38 \mathrm{mF} \mathrm{cm}^{-2}$ at $0.67 \mathrm{~mA} \mathrm{~cm}^{-2}$, an energy density of $3.4 \mu \mathrm{Wh} \mathrm{cm} \mathrm{c}^{-2}$, and a power density of $0.27 \mathrm{~mW} \mathrm{~cm}^{-2}$. Both the electrode-electrolyte interactions and the energy storage are influenced by the surface area of the electrode; specifically, $618 \mathrm{~m}^{2} \mathrm{~g}^{-1}$. The graphene foam-based supercapacitors (GFSCs) were bent under static and dynamic conditions and analyzed. The result was a stable GFSC with up to $68 \%$ capacitance retention throughout 25,000 charging and discharging cycles. The GFSC was also incorporated into a flexible self-charging power pack by integrating a flexible photovoltaic cell which continuously powered a wearable $\mathrm{pH}$ sensor.

Several challenges plague graphene-based fibers, including their loose porous structure; which causes low volumetric capacitance, and an unsatisfactory wettability when in contact with electrolytes. An approach to mitigate this problem is the wet-spinning of a non-liquid crystal dispersion of graphene oxide and CNTs (Figure 3C) [43]. With the help of a capillary orientation apparatus and chemical reduction, wet-spinning could be applied toward continuous hybrid fibers made up of reduced graphene oxide (RGO), fabricating CNTs as highly capacitive electrodes. The aligned CNTs aided the construction of a compact structure containing narrowly distributed mesopores within the continuous hybrid fibers. This enhanced the tensile strength of the fibers, improving internal electrical conduction of the fibrous electrode. Likewise, the RGO offered high pseudocapacitance due to its oxygen-containing groups. As a result, a higher volumetric capacitance of $355 \mathrm{~F} \mathrm{~cm}^{-3}$ and an energy density of $12 \mathrm{mWh} \mathrm{cm}^{-3}$ at a current density of $0.1 \mathrm{~A} \mathrm{~cm}^{-3}$ was observed while cycling stability of $94 \%$ was reached throughout 10000 cycles, showing bending durability. The evidence showed the stability of the supercapacitor, and possible applications for miniaturized flexible and stretchable energy devices.

Self-healing, flexible electronics possess a multitude of critical features that ensure long-term viability for personalized applications. There is a grand challenge in being able to realize high electro-conductivity, mechanical resilience and viscoelasticity, inherent mouldability, fast self-healing ability, and ideal electrochemical properties all in a device. For CNTs templated from nanocellulose and embedded in a viscoelastic polymer network, a dynamic crosslink between electrically conductive hydrogels was implemented (Figure 3D) [44]. This synthesis was created by homogeneously dispersing CNT cellulose nanofiber (CNT-CNF) nanohybrids into a viscoelastic polyvinyl alcohol (PVA)-borax gel matrix. The electro-conductive hydrogels displayed quick self-healing due to the dynamic, reversible complexation done by borate ions, PVA chains, and CNT-CNF nanohybrids. This carbon-based composite possessed capacitance retentions of $98 \%$ and $95 \%$ throughout 10 and 1000 breaking and self-healing cycles under different twisting, bending, and folding deformations, respectively. Based on these results, these materials have great promise for future applications in tailorable supercapacitors used in personalized electronics.

There are still difficult challenges in the way of developing large-scale production methods for flexible carbon-based supercapacitor devices in arbitrary shapes, let alone at a reasonable cost. Screen printing can be an alternative to provide mass fabrication with patterning capabilities [30,34]. For example, graphene composite films printed on screens could be a viable solution to this problem (Figure 3E) [34]. By combining the networked metal sulfide nanoflakes with reduced graphene oxide (RGO) nanosheets, the resultant material would be able to flex to the shape of any arbitrary solid-state hybrid supercapacitor. The films yield a high specific capacitance of $1739 \mathrm{~F} \mathrm{~g}^{-1}$ at a current density of $0.5 \mathrm{~A} \mathrm{~g}^{-1}$. This fabrication process can feasibly prepare fully printable supercapacitors and other electronic devices at a large scale, holding immense potential for the personalized technology field.

Apart from applications mainly used outside the body, one important class of personalized energy devices are implantable devices. There is a need for these devices to have high flexibility, especially 
when implanting in or near a blood vessel. For this specialized approach, a sample of the fiber is implanted into the vessel while the wound can be sutured with fiber-like stitching. To achieve this, a flexible implantable fiber supercapacitor is able to be applied in-vivo for energy storage. To fabricate these devices, a biscrolling process trapped poly(3,4-ethylenedioxythiophene):poly(styrenesulfonate) (PEDOT:PSS)/ferritin nanoclusters in multiwalled CNT (MWCNT) sheets which are electrically conductive and have high mechanical strength (Figure 3F) [45]. The MWCNT sheets used were taken from a spinnable MWCNT forest-grown via chemical vapor deposition (CVD). An important aspect to take into account is the device's biocompatibility. It should be noted that this concern is important, especially when carbon-based surfaces will come in contact with complex fluids and tissues. The MWCNT sheets could be coated with biocompatible materials, such as PEDOT:PSS and ferritin. This was seen in an in-vivo application where the abdominal muscle of a mouse was stitched with a suture resembling a micro-diameter sized fiber supercapacitor. The areal capacitance of the PEDOT:PSS/ferritin/MWCNT-based fiber supercapacitor in a phosphate buffer saline solution

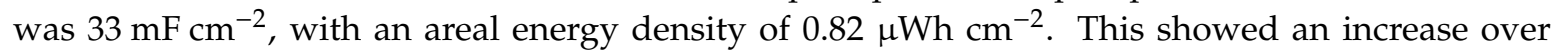
the guest-free MWCNT yarn, yielding values 52 times greater than the latter. Within the mouse, the supercapacitor exhibited biocompatibility and successful operation; seeing as how the capacitance maintained above $90 \%$ after eight days in-vivo.

\section{Moving Biofuel Cells toward Personalized Platforms}

In a conventional BFC, such as a glucose/oxygen BFC (Figure 4), a glucose metabolite serves as a fuel which is oxidized with the assistance of the biocatalyst immobilized at the bioanode to release electrons. The charge then flows into a current collector, such as the conductive carbon material-based electrode. Subsequently, these generated electrons are moved to the cathode. This cathode is the electrode where reduction (i.e., the acceptance of those generated electrons) takes place. $\mathrm{O}_{2}$ is a typical fuel on the cathode because of its natural availability and high $\mathrm{O}_{2} / \mathrm{H}_{2} \mathrm{O}$ redox potential.

These enzyme-based BFCs exemplify a different type of carbon-based energy-conversion device that is dissimilar from conventional fuel cells [46,47]. For instance, BFCs, based on biocatalysts, can operate under moderate conditions, such as in physiological media and at ambient or body temperatures. Outstandingly, compared with the noble-metal catalysts used in conventional fuel cells, the biocatalysts used in the BFCs are efficient and highly selective toward specific fuels. Moreover, advantages of these devices include viability in numerous potential applications, ranging from self-powered biosensors [48,49] to logic devices [50], as well as implantable modular power supplies [51]. The self-powered biosensing applications, based on the utilization of carbon-based BFCs, will be further discussed in Section 4. We will continue to elaborate on some BFC concepts and physical traits to support their viability toward personalized energy devices. 

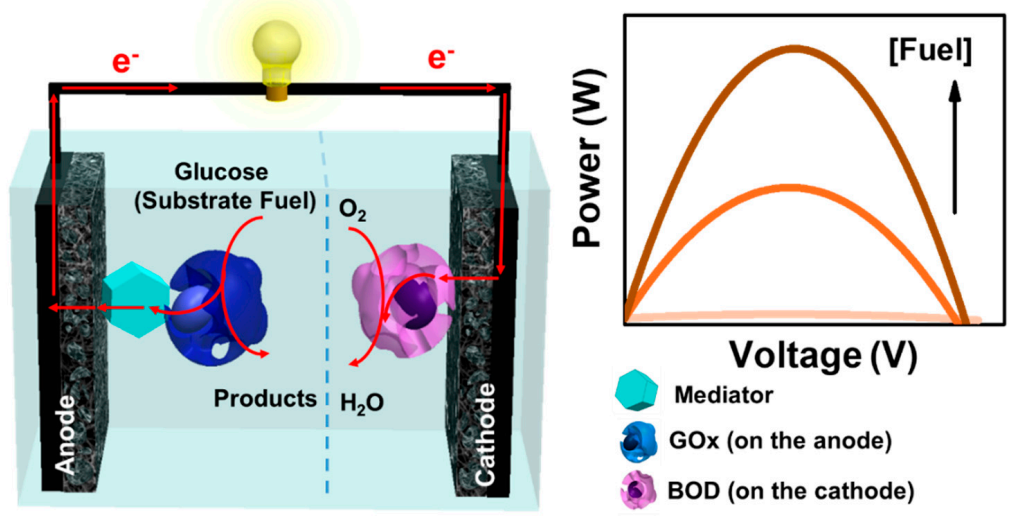

Figure 4. Illustration of a typical carbon-based glucose/oxygen BFC, showing the main components and principles involving enzymatic electro-oxidation and reduction on the anode and cathode, respectively. BFCs consist of a two-electrode cell, similar to other types of fuel cells. The BFC cell is separated by a medium, which could be an electrolyte and a separating membrane, which aids in conducting protons. However, because personalized devices require a miniaturized platform, a membraneless system is designed for simplicity.

The power output of the BFC is vital to the long-term sustainability of the biodevice. However, the output can be impeded by a variety of limitations. Of these, inefficient electron transference between enzyme molecules and the electrodes, hindrance of mass transport, low conductivity, and a small electrode active surface area pose the main threats. A solution to these complications is the incorporation of 3D graphene grown using the CVD method with single-walled CNTs (SWCNTs) (Figure 5A) [52]. Carboxylated SWCNTs interact with graphene via $\pi$-bonding and hydrophobic interactions. Using glucose oxidase (GOx) for the anode and laccase for the cathode, the carbon electrodes were functionalized using covalent bonding between the SWCNT's carboxyl group and an amino group of the enzyme proteins. The efficiency of electron communication between the biocatalyst and the carbon electrode can be seen in the electron transfer rate constant for the anode being $k_{s}=12.5 \mathrm{~s}^{-1}$. When equipping the electrodes composed of enzyme-functionalized SWCNT-decorated graphene, the BFC exhibited a high open circuit voltage of $\sim 1.2 \mathrm{~V}$ and an outstanding power density of $2.27 \mathrm{~mW} \mathrm{~cm}^{-2}$.

Laccase's role in many BFCs serves as a cathodic enzyme for the reduction of oxygen. This process is essential to the function of the bioenergy-harvesting device because it can directly reduce natural oxygen (available in the biofluids of an individual) to water via a 4-electron reduction cycle. As an example shown in Figure 5B, a mediated electron transfer by a 3D graphene network with 3,4,9,10-perylene tetracarboxylic acid and dopamine (3D-GNs-PTCA-DA) transfers electrons from the carbon electrode to the $T_{1}$ copper site of laccase, which happens to be the reduction center of the enzyme [53]. The flow of electrons then reaches the $\mathrm{T}_{2} / \mathrm{T}_{3}$ site containing $3 \mathrm{Cu}$ ions and is responsible for the reduction of $\mathrm{O}_{2}$ to $\mathrm{H}_{2} \mathrm{O}$. During the catalysis cycle, the laccase is oxidized by oxygen and turned over by a catechol species, while producing an $o$-quinone species. The catechol species can be regenerated at the 3D graphene networks electrode, proving the oxygen-consuming cyclical nature of the catalysis cycle. In order to functionalize this enzyme in the BFC device, 3D graphene networks (3D-GNs) acted in immobilizing the enzyme and its mediator on the electrode. The 3D-GNs were synthesized using a combination method between $\mathrm{Ni}^{2+}$-exchange and $\mathrm{KOH}$ activation. The graphene networks' wall is composed of very few layers, which yielded a small thickness of $\sim 4 \mathrm{~nm}$. The analysis of the 3D graphene networks (3D-GNs) showed a large surface area of $2153 \mathrm{~m}^{2} \mathrm{~g}^{-1}$, as well as an abundant distribution of mesopores in the structures at a 2-9 nm range. A glucose/oxygen BFC composed of Nafion/GOx/ferrocence/3D-GNs/GCE in the anode and Nafion/Laccase/3D-GNs-PTCA-DA/GCE in the cathode was able to output a power density of $112 \mu \mathrm{W} \mathrm{cm}{ }^{-2}$, indicating that 3D-GNs are a viable carbon substrate in retaining high enzymatic activity. 


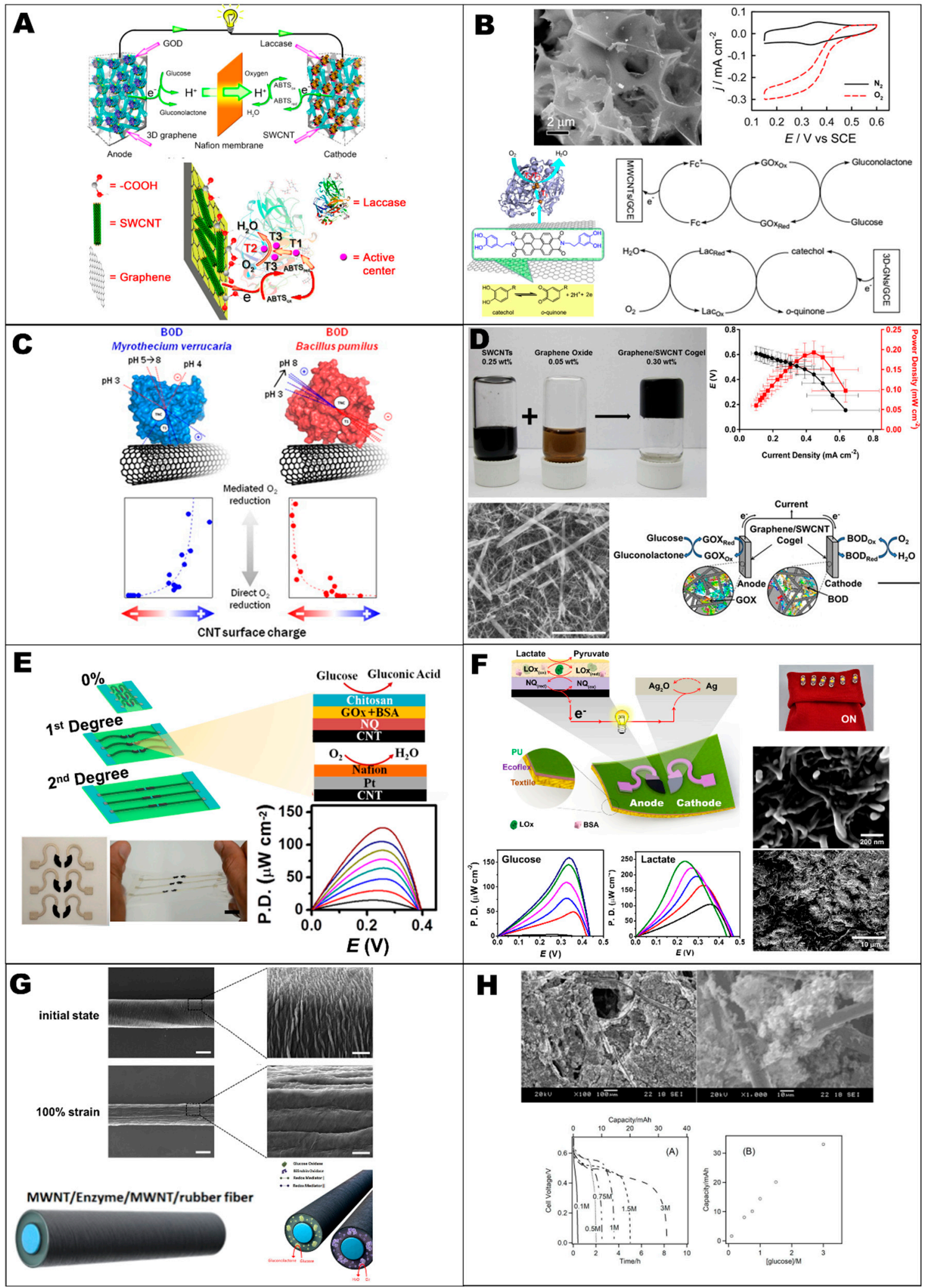

Figure 5. Examples of applications of carbon materials for biofuel cells (BFCs) and potential opportunities toward the development of personalized BFCs. (A) 3D graphene-CNT hybrid BFCs. Adapted with permission from [52], Copyright 2014, American Chemical Society. (B) 3D graphene networks as a substrate for immobilization of enzymes for BFCs. Adapted with permission from [53], 
Copyright 2014, American Chemical Society. (C) Study of interactions between CNTs and bilirubin oxidases (BODs) to control direct and mediated $\mathrm{O}_{2}$ reduction. Adapted with permission from [54], Copyright 2016, American Chemical Society. (D) Freestanding cogels of graphene and SWCNT used for BFCs. Adapted with permission from [55], Copyright 2015, American Chemical Society. (E) Highly stretchable CNT-based BFCs. Adapted with permission from [56], Copyright 2016, American Chemical Society. (F) Wearable textile-based BFCs using CNT-based electrodes. Adapted with permission from [15], Copyright 2016, The Royal Society of Chemistry. (G) Rewrapping MWCNT sheets for stretchable fiber BFCs. Adapted with permission from [57], Copyright 2018, American Chemical Society. (H) Flexible carbon cloth modified with MgO-templated porous carbon for BFCs. Adapted with permission from [58], Copyright 2019, Elsevier.

Nanomaterials such as CNTs can enable direct contact to the enzymatic reaction center $[54,59,60]$. Because of this, more favorable electron transference between the CNTs and enzymes can be achieved, e.g., within the mediatorless carbon GOx bioelectrodes [59]. The study of enzyme and carbon nanomaterial interactions is vital to understanding how to compose the most efficient electrochemical interface designs. As shown in Figure 5C, several interactions of importance included the interactions between different bilirubin oxidases (BODs), and the bearing of certain pristine, carboxylic-, and pyrene-methylamine-functionalized charges on the CNT surface [54]. Neutral, negative, and positive interfaces were provided by three different types of CNTs. These include pristine (no significant charge), $\mathrm{COOH}$-functionalized (negative charge), and pyrenemethylamine-functionalized (positive charge). By adjusting the solution's $\mathrm{pH}$ during enzyme adsorption, an optimal enzymatic orientation was achieved. In the two tested BODs, which could be incorporated in the BFC cathodes, the fungus Myrothecium verrucaria ( $M v$ BOD) and bacterium Bacillus pumilus (Bp BOD) exhibited differing electrochemical traits. The highest DET current for $M v$ BOD was observed at negatively charged surfaces of nanocarbon electrodes, while the $B p$ BOD yielded its highest catalytic response on positively charged surfaces at their most viable $\mathrm{pH}$. As the zeta potential of $\mathrm{Mv}$-based carbon electrode was increased, the MET/DET ratio increased, whereas in $B p$ the MET/DET ratio decreased as the zeta potential was increased.

Another case involved the use of graphene and a single-walled CNT cogel to develop a membrane/mediator-free BFC as shown in Figure 5D [55]. The carbon-based cogel occupied a large surface area of $\sim 800 \mathrm{~m}^{2} \mathrm{~g}^{-1}$ while enabling high enzyme loading, unhindered transport through large porosity, and an electrical conductivity of $\sim 0.2 \mathrm{~S} \mathrm{~cm}^{-1}$. In order to reduce the loss of electrons to outside electron acceptors, such as molecular oxygen, large quantities of the functioning enzyme within the device were incorporated to surround the enzyme with conductive carbon material. This potentially reduces the leaching of enzymes during operation as well. The BFC produced a power density up to $0.19 \mathrm{~mW} \mathrm{~cm}^{-2}$ with an open-circuit voltage of $0.61 \mathrm{~V}$. The preparation of the SWCNT cogel consisted of sonicating SWCNTs in sodium dodecylbenzenesulfonate (SDBS). Synthesized graphene oxide was added to the solution, and gelled within hours via slow water evaporation. The SDBS surfactant was removed from the cogels through rinsing with nitric acid and water. Hydrothermal reduction $\left(185^{\circ} \mathrm{C}\right)$ converted the graphene oxide to graphene. Water was then exchanged with ethanol at rising ethanol concentrations, and the cogels transformed into acrogels via critical point drying. The graphene was finally reduced with pyrolysis $\left(900^{\circ} \mathrm{C}\right)$ and yielded the final graphene/SWCNT aerogels. The resulting carbon cogel can be used to immobilize enzymes for transport when fabricating BFC electrodes. This enzyme loading is achieved by incubating individual graphene/SWCNT hybrid aerogels in an enzyme solution. However, in general, a limitation to this is the collapse of the carbon structure during the loading. In order to completely induce enzyme loading to the electrodes without collapsing the cogels, a weak pulsed vacuum was applied for several minutes via a vacuum pump before incubation.

In order to successfully integrate stretchable electronics for widespread use, such as in wearable applications, one could leverage specially engineered inks in a screen-printing process with a careful electrode design pattern for additional stretchability. This process yielded highly stretchable CNT-based 
electrochemical devices able to withstand the extreme tensile strain, as presented in Figure 5E [56]. The specific carbon ink used is composed of a CNT and polyurethane mix, which provides intrinsic stretchable properties. The CNTs contribute exceptional electrical and mechanical properties to complement the elastomeric polyurethane binder. The resultant device is printed and can endure extreme stress due to the synergy of its design pattern and specifically engineered ink. Consequently, two levels of stretchability are offered by the ink: the unwinding, free-standing serpentine connections, and the intrinsic stretching of the ink. The wide range applicability of stretchable CNT electrodes in electrochemical sensors is not only restricted to fabricating BFCs, but includes the characterization of potentiometric ammonium sensors, amperometric enzyme-based glucose sensors, enzymatic glucose BFCs, and self-powered biosensors.

Textile also provides an important platform for wearable electronics occupying larger surface areas. The material can be cut to the size needed and printed on with ease, allowing for a resilient, stretchable material that would conform to the wearer. A specifically engineered CNT-based composite ink was utilized in the printed devices due to the favorable conductive properties of CNTs in bioelectronics processes (Figure 5F) [15]. The high aspect ratio of CNT, being 1300, promotes the percolation of ink within its matrix. This action improves stretchability by percolating the electrode structure with the CNT embedded as a nanofiller. The CNT percolation serves to facilitate the flow of electrons in electrochemical processes. The resulting printed structure could allow for the fabrication of glucose and lactate-based BFCs with single-enzyme, membrane-free configurations able to generate power densities of 160 and $250 \mu \mathrm{W} \mathrm{cm}{ }^{-2}$ and open-circuit voltages of 0.44 and $0.46 \mathrm{~V}$, respectively.

In addition, CNT yarns serve an important role in the personalization of energy devices due to their excellent stretchability and properties when integrated with electronics. These fiber-shaped structures are fabricated for wearable technologies by coating layers of active materials and electrodes on top of one another onto fiber substrates or carbon electrodes. These are an improvement over traditional fibers, which suffer from limited stability and flexibility, yielding less than ideal performance [61]. Efforts have been made to replicate stretchable properties into a carbon-based BFC by incorporating rewrapped multiwalled CNT (MWCNT) sheets onto the rubber fiber. (Figure 5G) [57]. The MWCNT-rubber fibers took on several roles: as an underlying electrode where the enzyme was immobilized, as a cross-linker, and as an osmium-based redox polymeric mediator. The active biocatalytic layer-coated electrode was later wrapped with MWCNT sheets, trapping the enzyme between the sheets. The highly conductive porous structure of the MWCNT sheet allows for faster electron transport generated from glucose and oxygen during oxidation and reduction. The porous structure of the MWCNT sheet also assists in the mass transference of glucose and oxygen as well. The resulting fiber thickness was $\sim 380 \mu \mathrm{m}$ and was able to stabilize the BFC and retain its power density during external stretching. Measurements taken during stretching showed a linear resistance slightly increasing in the initial stage and becoming stable. The resistance increased from 510 to $600 \Omega \mathrm{cm}^{-1}$ on stretching to $100 \%$ strain, and even then, was able to return to its original resistance after release. The anodic component relied on GOx mediated oxidation, while the cathode employed a BOx mediated oxygen reduction reaction (ORR) process. This fiber-based BFC was able to endure stretching of up to $100 \%$ while producing sustainable electrical power.

$\mathrm{MgO}$-templated carbon $(\mathrm{MgOC})$ is an example of a carbon material that possesses a high surface area, making it promising for electrochemical energy applications [62-64]. MgOC's tunable pore size distribution of $2-150 \mathrm{~nm}$ could be modulated by adjusting the crystalline structure in the $\mathrm{MgO}$ template. The ability to adjust the distribution of the pore size gives $\mathrm{MgOC}$ an advantage over other mesoporous carbons. The interconnected mesopores in MgOC provided a desirable, large effective surface area per volume in order to facilitate enzyme immobilization. The mesopore size in the resultant carbon could be engineered for an ideal distribution by selecting the $\mathrm{MgO}$ precursor and tuning the volume between mesopores and micropores controlled by the carbon precursor. $\mathrm{MgO}$ has been chosen as the template for porous carbon fabrication due to its chemical and thermal stability, lack of structural and compositional changes, lacking a reaction with carbon up to the carbonization 
temperature of carbon precursors, and being able to easily dissolve into a diluted acidic solution. In a flexible, glucose- $\mathrm{O}_{2}$ enzymatic $\mathrm{BFC}$, porous carbon and carbon cloth were necessary to retain the desirable properties; this example is shown in Figure 5H [58]. The electrodes were made up of a carbon textile composite, and were fabricated based on the MgO-template. The advantages sustained by these materials allow the electrodes to be lightweight, flexible, and able to contain liquid. MgOC particles, in particular, possessed a pore size of $40 \mathrm{~nm}$ and $1.2 \mu \mathrm{m}$ diameter. At the anode, flavin adenine dinucleotide-dependent glucose dehydrogenase (FAD-GDH) from Aspergillus terreus was used, with 1,4-naphthoquinone selected as the redox mediator. At the reduction site in the cathode, BOD from Myrocecium verucaria and 2,2'-azinobis(3-ethylbenzothiazolin-6-sulfonate) (ABTS), mediated electron transfer between the BOD active site and the electrode. In the cathode region, ABTS adsorbed on the MgOC electrode surface sped up electron transfer rates by improving the physical orientation of BOD on the carbon surface, and by mediating the electron flow from the electrode to BOD's active site. The maximum power output density of the BFC was $2 \mathrm{~mW}$ at $0.4 \mathrm{~V}$, with an open circuit potential of $0.75 \mathrm{~V}$. The data showed that the BFC based on a pore size-controlled, MgOC-coated carbon textile electrode was viable for possible use in wearable energy biodevices.

\section{Futuristic Self-Powered Biosensors Based on Biofuel Cells}

Advancements in biosensor technologies have resulted in a variety of personalized diagnostic and monitoring devices. However, almost all bioelectronics require energy sources to manipulate and signal the analytical result. In addition to harvesting energy applications, BFC-based devices also offer unique opportunities to act as self-powered biosensors (Figure 6). For example, as the glucose or lactate level increases (that is, the biofuel or bioanalyte level increases), a correlation to higher electrical power can be obtained. In other words, the electrical signals harvested from the biofuels themselves can indicate the concentration of the target analytes. The electrical power obtained from the BFC could sufficiently power electronics. For instance, a complementary metal-oxide-semiconductor (CMOS) wireless biosensing system tracking glucose and lactate concentrations, which consume $\sim 1.2 \mu \mathrm{W}$ of power, could be solely powered by BFCs [65]. In addition to directing the self-powered detection of metabolites, BFC-based devices have been applied for various other detection mechanisms $[48,49]$.
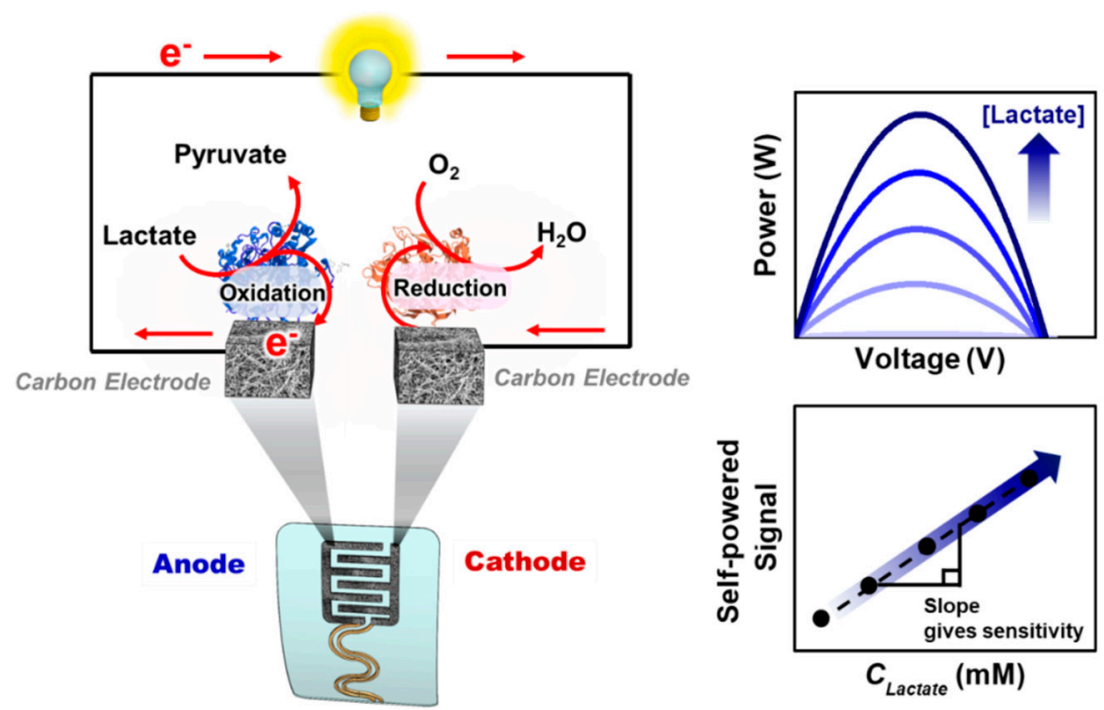

Figure 6. Conceptual illustration of a simple example of the application of BFC energy harvester for self-powered biosensors, such as lactate biosensing application.

Stretchable carbon-based BFCs, used as wearable self-powered sensors, have held enormous potential for personalized technology [15]. Smart carbon-based textiles have recently acquired popularity in various applications due to their ability in covering larger surface areas. These materials 
can integrate with human skin morphology, providing convenience and practical applications [66]. The emerging concept of self-powered textile biosensors can be seen by leveraging BFCs (Figure 7A) [15]. Glucose and lactate-based BFCs functionalizing single enzymes and membraneless formations were fabricated via a screen-printing process on stretchable CNT-based electrodes. In order to gauge the success of the stretchability, intrinsic properties of custom-made flexible materials and serpentine patterns were printed onto non-conductive textile substrates. Any self-generated electrical signals were proportional to the concentrations of sweat, glucose, or lactate biofuels. When evaluating the existence of human sweat constituents, the self-powered sensor was highly selective to the analyte target. Besides their enzymatic specificity, these BFCs can minimize the effects of analytical interference due to their lack of any additional external voltage applied to the sensor, which decreases the interfering signal from the co-existing electroactive species, such as ascorbic acid. A wireless device can complement the wearable sensor in order to record the real-time lactate signal from a smartphone. The in-vivo analytical-chemistry-on-a-textile demonstration confirmed the ability of innovative carbon-based BFC biosensors to be used under physical exertion during biking. This first example of the advancement in wearable carbon-based biosensors with real sweat is an exciting prospect for mechanically resilient self-sustaining biodevices.

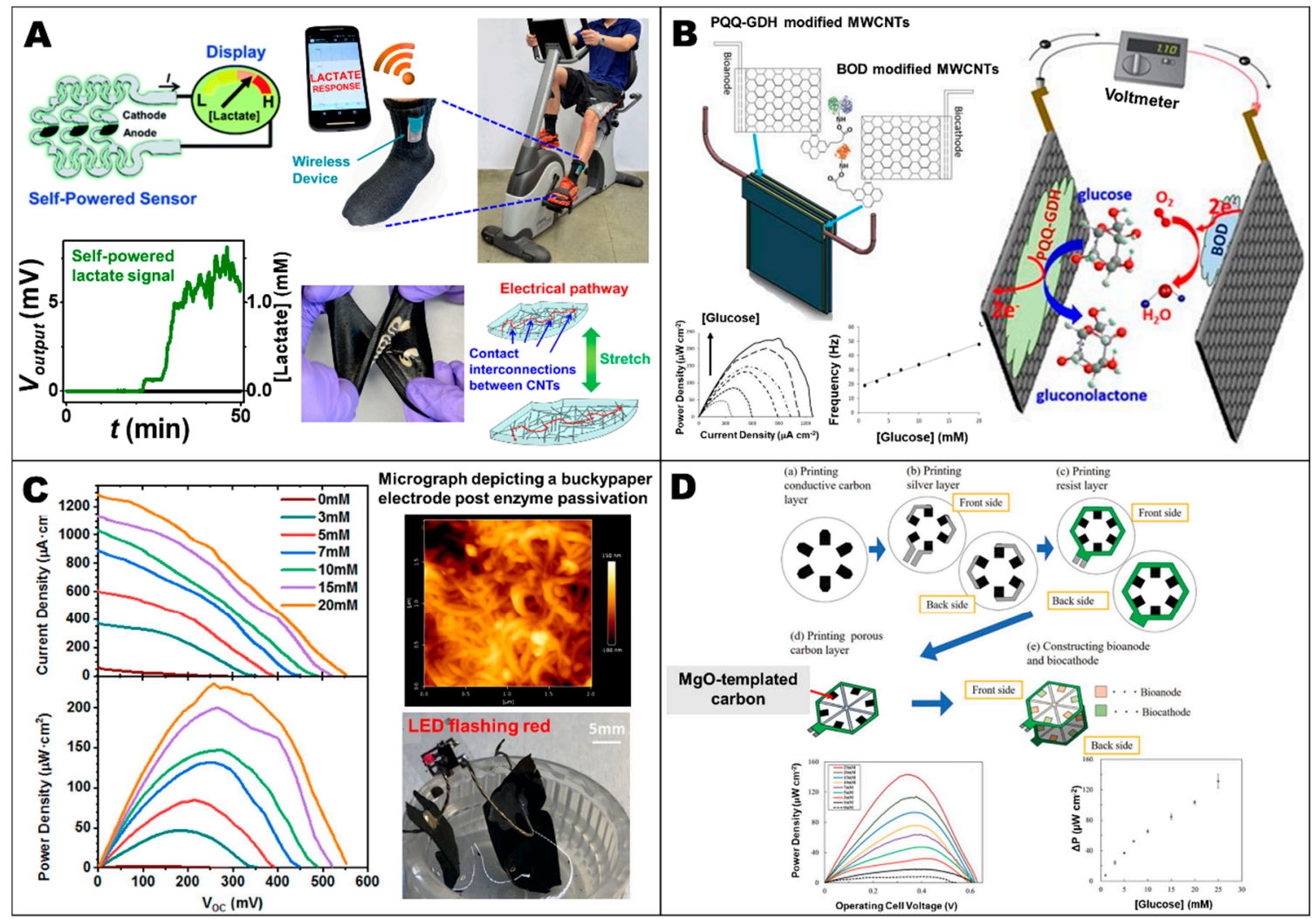

Figure 7. Examples of applications of carbon materials for self-powered sensors. (A) Wearable textile-based self-powered sensors, utilizing stretchable CNT-based electrodes. Adapted with permission from [15], Copyright 2016, The Royal Society of Chemistry. (B) Self-powered glucose sensor, utilizing a capacitor circuit and CNT-based electrodes. Adapted under the terms and conditions of the CC-BY license from [67], Copyright 2017, Slaughter et al., published by Nature Publishing Group. (C) Fully flexible autonomous glucose indicator, utilizing buckypaper-based bioelectrodes. Adapted under the terms and conditions of the CC-BY from [68], Copyright 2019, Yuen et al., published by Nature Publishing Group. (D) Self-powered glucose biosensor, utilizing screen-printed MgO-templated carbon electrodes. Adapted under the terms and conditions of the CC-BY license from [69], Copyright 2019, Shitanda et al., published by the Electrochemical Society. 
For this application, the concept of a battery-free wireless electronic sensor was conceived by substituting harvested electrical power from carbon-based BFCs. Another example is a selective glucose sensor, which was able to be created using a capacitor circuit while generating power for a microelectronic device [67]. For fabricating BFCs, MWCNTs were modified with pyrroloquinoline quinone glucose dehydrogenase (PQQ-GDH) at the anode and BOD at the cathode. The glucose-based $\mathrm{BFC}$ exhibited a linear peak power vs. concentration relationship at a concentration range of 3 to $20 \mathrm{mM}$. The input voltage from the BFC reached a low of $0.25 \mathrm{~V}$, and was converted to stepped-up power and charged at the capacitor to a voltage of $1.8 \mathrm{~V}$. The frequency of the charging and discharging cycle in the capacitor directly correlated to the oxidation of glucose. This frequency dependence was used for self-powered electroanalytical chemistry and determining glucose levels.

Another example is shown in Figure 7C, describing further efforts toward developing a fully-flexible, self-powered system capable of indicating the presence of glucose [68]. The system takes advantage of the combination of two flexible electronic technologies. The first is the flexible self-powering BFC, while the second is a flexible electronic device; in this case, a circuit-board decal made from biocompatible microbial nanocellulose. One critical advancement in this field is the advent of aggregated multi-walled carbon nanotubes (MWCNTs) known as buckypaper. Buckypaper has been functionalized to be used as the underlying support when fabricating BFCs including compliant electrodes [70,71]. Within CNT papers, redox molecules are embedded as the electrical wiring for the enzymes. This BFC is composed of MWCNT sheets functionalized with a heterobifuntional crosslinker known as 1-pyrenebutanoic succinimidyl ester, resulting in $\pi-\pi$ stacking of the pyrene moieties along the MWCNT walls. These materials form a peptide bond with the lysine group of the enzyme, which crosslinks the MWCNTs with the biocatalyst. The anode of the BFC was comprised of pyrroloquinone quinone glucose dehydrogenase (PQQ-GDH) covalently attached to 1-pyrenebutanoic succinimidyl ester modified MWCNTs to aid in glucose oxidation. The cathode incorporated BOD in order to catalyze the ORR reaction. Additionally, the physical texture of the buckypaper allowed a high volume of the analyte sample to be wicked into the bioelectrodes due to its porosity. The analyte sample is retained in the bioelectrodes for a long duration in order to facilitate stable power production for powering small electronic devices connected to the body. The enzymatic glucose BFC was able to function as a glucose sensor and a light-emitting diode (LED) indicator. The supplementary functions of the device did not require additional electronic equipment, using all on-board electronics. The resulting indicator was shown to be able to operate at a high sensitivity within linear glucose concentration ranges $1-45 \mathrm{mM}$ glucose continuously, achieving a $1.8 \mathrm{~V}$ output from a flexible indicator system that also delivered the power to drive the LED circuit.

Another approach taken involved utilizing a screen-printed carbon electrode with the capability to produce an array of a specific desired design, as seen in Figure 7D [69]. A six-glucose/ $\mathrm{O}_{2}$ BFC array connected in series was able to be patterned. The electrode possessed a self-powered glucose sensor that exhibited a net electromotive force of $3.2 \mathrm{~V}$. However, the porous structure of the electrode must have been developed in order to retain the desired electrochemical properties. $\mathrm{Mg}$-O templated carbon $(\mathrm{MgOC})$ particles that had a pore size of $100 \mathrm{~nm}$ were able to be applied in the paper-based self-powered glucose biosensor. The fabrication of the $\mathrm{MgO}$-templated carbon involved screen printing on water repellant paper in order to replicate the formation of porous carbon electrodes. By kneading $\mathrm{MgOC}$, poly(vinylidenedifluoride) binder, and N-methylpyrrolidone solvent, the porous carbon ink was able to be synthesized. This process took a minute of continuous mixing in a rotation revolution mixer. The resulting porous carbon ink was then printed and dried at $60^{\circ} \mathrm{C}$. This allows for mass transfer of glucose and ions through the carbon layer without disruption from the enzyme being adsorbed on the electrode surface at high enzyme loading. The high specific surface area of $\mathrm{MgOC}$ also assists in preventing any disruption. The porosity of carbon was vital to improving the cathodic reaction capabilities on the cathode and avoided the main limitations at the cathodic reaction. The cathode contained BOx as a catalyst for oxygen reduction, while the bioanode contained GOx as the catalyst and tetrathiafulvalene as a mediator. By utilizing MgO-templated carbon, the cathode enzymatic electrochemical reactions 
and mass transfer of fuels throughout the carbon materials was significantly improved. The device suggested the possibility to be used in diagnosing diabetes, where the dependence of the glucose concentration output power was found in the range 1-25 $\mathrm{mM}$.

\section{Challenges in Carbon-Based Material Energy Devices and Potential Solutions}

\subsection{Electron Transfer between Carbon Materials and Enzymes}

Electrochemical performances of carbon-based enzymatic BFCs are strongly dependent on 'wiring'. This 'wiring' term is referred to the electron communication system between the enzymatic active site and the carbon material support. Direct electron transfer between the enzyme and the electrode allows the operation in an optimum potential close to the redox potential of the enzyme itself, and this consequently maximizes the BFC voltage and total power output. Non-optimal electrical wiring will limit the energy-conversion performance in enzymatic BFCs. Therefore, careful attention is needed to address major challenges related to electrical wiring by engineering effective carbon materials, new composites, and enzyme immobilization.

GOx and lactate oxidase (LOx) are among the most common enzymes employed to build wearable BFC energy converters [4]. For instance, GOx includes a dimer of two $80 \mathrm{kDa}$ subunits and a firmly bound flavin adenine dinucleotide (FAD) cofactor [72]. FAD is the chief electroactive redox center (a redox potential of $-0.044 \mathrm{~V}$ vs. $\mathrm{Ag} / \mathrm{AgCl}(3.5 \mathrm{M} \mathrm{KCl})$ at $\mathrm{pH} 7)$ [73]. The enzymatic system, including a $\mathrm{FAD} / \mathrm{FADH}_{2}$ process, involves electron transfer and specific oxidization of $\beta$-d-glucose to gluconolactone. Nevertheless, this FAD center is shielded in the protein and a glycan structure. Such an external barrier obstructs the electron transfer at the electroactive site-conductive electrode boundary, presenting a big limitation. Unavoidably, this needs tremendous research efforts to resolve this difficulty of the electron transfer in order to maximize the energy-conversion performance [74-76].

Two strategies have been developed to wire enzymes to the carbon electrode. These approaches are (1) mediated electron transfer (MET) and (2) direct electron transfer (DET, referring to mediatorless electron transfer between the enzyme and the electrode).

First, a redox mediator, which plays an important role as an electron-shuttle assistant between the enzymatic active site and the electrode, can be employed in the MET approach. Importantly, the suitable mediator can boost the heterogeneous electron transfer rate to the order of a homogeneous transfer [77]. The primary consideration of this strategy is the selection of an appropriate mediator that should be close to the redox potential of the enzymatic active center, such as $\mathrm{FAD} / \mathrm{FADH}_{2}$, to enable proficient electron shuttle between the enzyme and the conductive carbon material. It should be noted that the choice of mediator strongly affects the BFC cell voltage and stability. In theory, glucose anode $/ \mathrm{O}_{2}$ cathode $\mathrm{BFCs}$ should display a maximum thermodynamic reversible cell voltage of $1.18 \mathrm{~V}$ [78]. However, real BFCs with MET-based electrodes cause thermodynamic losses due to MET, hence displaying a smaller cell voltage [79]. For example, FAD/FADH ${ }_{2}$ shows a potential of $-0.044 \mathrm{~V}$ vs. $\mathrm{Ag} / \mathrm{AgCl}(3.5 \mathrm{M} \mathrm{KCl})$, while $\mathrm{Os}^{2+} / \mathrm{Os}^{3+}$ in the polymeric Os-complex, used in MET-based graphite electrode, displayed a higher redox potential of $0.436 \mathrm{~V}$ vs. $\mathrm{Ag} / \mathrm{AgCl}(3.5 \mathrm{M} \mathrm{KCl})$. This potential difference between the enzymatic active site and the mediator can cause an unfavorably decreased cell voltage. However, this mediated anode-based BFC, functionalized with the redox polymer and the incorporated enzyme, displayed a higher experimentally measured OCV compared to the thermodynamically estimated value [73]. This advantageous capability is a result of charge storage upon catalytic conversion on carbon materials due to the use of redox polymers immobilized on the graphite surface. In addition, mediated electron transfer can enhance the current output [80]. For example, 1,4-naphthoquinone can be used as a mediator, providing higher catalytic activity, compared with the DET [80]. This 1,4-naphthoquinone, coupled with 10-nm-diameter MWCNTs, offers an effective anode relying on the MET oxidation of glucose by GOx. The resulting glucose $/ \mathrm{O}_{2}$ displayed a high OCV of 0.76 and a maximum power of $1.54 \mathrm{~mW} \mathrm{~cm}^{-2}$. 
Biocompatibility of mediators is an issue for on-body applications. Despite the positive advantages of using mediators, researchers are interested in exploring safer mediators or eliminate the use of mediators altogether. Possible solutions are utilizing nanomaterials or employing highly biocompatible natural catalysts. For instance, capable mediatorless ethanol BFCs can be developed by applying natural electrocatalysts available in mushroom/plant extracts to catalyze reactions for ethanol BFCs [81]. This 'green' approach relies on the natural biocatalysts and edible charcoal material, representing an alternative for carbon-based BFCs. This example opened opportunities for carbon-based devices will come in contact with biosystems.

Furthermore, the DET strategy is an ideal route for enzymatic electrical wiring. Carbon nanomaterials have been used to help direct electron transference between the enzyme active site and electrode. This strategy relies on the close contact of the active enzyme and the nanomaterial $(\sim 1.5 \mathrm{~nm})$ where the electroactive redox center of the biocatalyst can be connected directly by the electrode [82]. For example, CNTs have played an important role in incorporating enzymes into electronic circuitry. Particularly, these CNTs establish electrical communication with enzymes due to their intrinsic conductivity, or via electrons hopping to enzymes between immobilized redox locations. Regarding their miniscule scale, CNTs can accurately approach the prosthetic enzyme site with close proximity, therefore directly wiring the enzymes and the bulk electrode $[60,83]$. Note that some articles discuss that there is no clear indication to uphold the assertions of DET for native GOx at CNT- or graphene-based electrodes [84]. In theory, the DET tactic can maximize the performance of BFCs, particularly optimizing the potential output. Nevertheless, it should be noted that many reported BFCs use the MET strategy since mediator-based BFCs usually display high current performance [79]. Achieving effective wiring of carbon materials with the redox center is one of the most challenging subjects remaining that requires the consideration of the orientation of the enzymatic active site embedded in the shielding shell and the protein architecture $[74,85]$.

\subsection{Oxygen Reduction Reaction in Biofuel Cells}

The natural availability of $\mathrm{O}_{2}$ and a high $\mathrm{O}_{2} / \mathrm{H}_{2} \mathrm{O}$ redox potential has led to much attention toward developing $\mathrm{O}_{2}$-based cathodes for personalized energy applications. The four-electron ORR potential in alkaline solutions is $0.401 \mathrm{~V}$ vs. SHE or $0.196 \mathrm{~V}$ vs. $\mathrm{Ag} / \mathrm{AgCl}(3.5 \mathrm{M} \mathrm{KCl})$, while the ORR potential in acid solutions is $1.229 \mathrm{~V} \mathrm{SHE}$ or $1.024 \mathrm{~V}$ vs. $\mathrm{Ag} / \mathrm{AgCl}(3.5 \mathrm{M} \mathrm{KCl})$ [86]. A variety of carbon materials with ORR catalysts, such as enzymes or inorganic catalysts, have been developed to improve high catalytic current and cathodic potential. For example, a hydrophilic carbon cloth (78\% void fraction, $350 \mu \mathrm{m}$ thickness, $10 \mathrm{~mm}$ fiber diameter) functionalized with a laccase biocatalyst and an Os-based redox polymer can catalyze four-electron reduction of oxygen to water, yielding a high current density of $5 \mathrm{~mA} \mathrm{~cm}^{-2}$ and at $0.495 \mathrm{~V}$ vs. $\mathrm{Ag} / \mathrm{AgCl}(3.5 \mathrm{M} \mathrm{KCl})$ [87]. Moreover, compared with common MWCNTs, nitrogen-doped MWCNTs can enhance the electrocatalytic activity of the reduction of $\mathrm{O}_{2}[88,89]$. The enhanced electrocatalysis is because of rich oxygen-containing groups and the nitrogen-induced charge delocalization at the nitrogen-doped carbon material, which changes the chemisorption mode of the essential $\mathrm{O}_{2}$ adsorbate.

However, $\mathrm{O}_{2}$ solubility and the diffusion coefficient in water is about $1.2 \mathrm{mM}$ and $\sim 2 \times 10^{-5} \mathrm{~cm}^{2} \mathrm{~s}^{-1}$, respectively (at $25^{\circ} \mathrm{C}$ and $1.0 \mathrm{~atm}$ ) [90]. In addition to the limited diffusion coefficient and low levels of oxygen, fluctuation of concentration levels of dissolved oxygen in biofluids such as sweat, biological tissue, and blood can restrict the cathodic performance in the personalized BFC energy converter. Therefore, careful attention must be given to developing the cathode. For instance, a $\mathrm{Ag}_{2} \mathrm{O} / \mathrm{CNT}$ composite is a helpful candidate to address this challenge because $\mathrm{Ag}_{2} \mathrm{O} / \mathrm{Ag}$ provides a high potential of 0.342 vs. SHE, similar to $\mathrm{O}_{2} / \mathrm{OH}^{-}\left(0.401 \mathrm{~V}\right.$ vs. SHE) at $\mathrm{pH} 7[15,91]$. The carbon blended with $\mathrm{Ag}_{2} \mathrm{O} / \mathrm{Ag}$, which is not reliant on the ORR, can be applied to the BFC cathode, minimizing the $\mathrm{O}_{2}$-related effect. Moreover, carboxylic acid-functionalized MWCNTs can be mixed with polychlorotrifluoroethylene and the active $\mathrm{Pt}$ catalyst to fabricate an $\mathrm{O}_{2}$-rich cathode [92]. This $\mathrm{O}_{2}$-rich carbon-paste cathode allows a glucose/oxygen BFC to operate under oxygen-free conditions, mitigating the power loss in an 
oxygen-free medium or during external oxygen fluctuations through an internal supply of oxygen. In addition, highly electro-conductive carbon black (Brunauer-Emmett-Teller (BET) surface area of $\left.800 \mathrm{~m}^{2} \mathrm{~g}^{-1}\right)$, coupled with a polytetrafluoroethylene binder, can be used to construct an effective air-diffusion biocathode with multi-copper oxidase (from Escherichia coli) [93]. Such carbon black and polytetrafluoroethylene composites provide the hydrophobicity on the cathode surface, allowing the direct use of $\mathrm{O}_{2}$ from the air, and alleviating the effects of low oxygen concentration.

\subsection{Stability of Enzymes in Carbon-based Electrodes}

Some of the especially decisive challenges in enzyme-based energy harvesters are the shelf-life and operational stability. Active components, including enzymes and mediators, may leach out from the carbon support and electrode matrix during operations. Therefore, several efforts have been made to stabilize enzymatic BFC electrodes.

An effective approach to enhance stability is to integrate stabilizers with electrodes. Polyelectrolytes, dextrans, glycerol, polyethyleneimine, and hydrophobic oils can be used as stabilizers [94-96]. Additionally, the high surface area of porous carbon materials helps to entrap the active materials and stabilizers. For example, mixing carbon with a hydrophobic pasting liquid, such as mineral oil or silicone grease, is a strategy to construct a stable enzymatic carbon composite $[92,95,96]$. The hydrophobic binder offers favorable conformational rigidity for the enzyme environment, lower protein mobility, and shield hydronium ions from the acidic environments. This approach is helpful to stabilize many carbon-based enzymatic electrodes, such as electrodes including GOx, LOx, alcohol oxidase, horseradish peroxidase, amino acid oxidase, or polyphenol oxidase. Moreover, a highly extended porous architecture with porous diameters of 100-300 $\mathrm{nm}$ and small nanopores (diameters smaller than $70 \mathrm{~nm}$ ) could be used [97]. The high surface area and surface adsorption efficiency of enzymes in this material matrix are brought about by the extended porous structure of the material. Compared to the free enzyme-loaded hydroxyethylcellulose membrane, the leaching rate of the porous carbon-loaded membrane decreased 2.5 times, which is useful for ensuring operational stability in enzymatic carbon electrodes. This is particularly important for in-vivo applications.

\subsection{Electrochemically Accessible Surface Area of Porous Carbon Materials}

Highly porous carbon is useful for both energy-storage and energy-conversion devices. The specific surface area of carbon materials is a general parameter for indicating the electrochemical performance of carbon materials. However, the real structure and pore size distribution of carbon materials are also significant factors that affect the actual power performance and electrochemically accessible surface area. For instance, only partial micropores of carbon are electrochemically accessible to electrolyte ions. The evidence shows that there is no linear correlation between the specific surface area and the capacitance [98]. Exceptionally small pores (less than $0.5 \mathrm{~nm}$ ) hinder the accessibility of hydrated ions. Note that the International Union of Pure and Applied Chemistry (IUPAC) classifies porous materials into three groups: macroporous (pore diameter $>50 \mathrm{~nm}$ ), mesoporous $(2-50 \mathrm{~nm})$, and microporous $(<2 \mathrm{~nm})$ [99]. In other words, carbon materials possessing higher percentages of micropores may limit net electrochemical performances. This leads to challenges in enhancing the capacitance and real electrochemical performances. Therefore, selecting and tuning materials are vital tasks for optimizing performances of electrochemical energy devices.

Large surface area materials have many advantages for enzymatic BFCs [100]. Macropores can facilitate the diffusion of fuels to access the catalytic location, while mesoporous carbon increases the entrapment of enzymes or active components, such as redox mediators. Overall, 3D carbon electrodes with interconnected hierarchical porosity offer the fabrication of high-current-output energy devices. For example, porous electrodes, prepared by using a hard-template method, can be modified further with GOx and Os polymers. Such a carbonaceous, large foam-based electrode (with the macroscopic pore size distribution of 4-5 $\mu \mathrm{m}$ ) displayed a 13-fold higher current of glucose electrooxidation, compared with using a glassy carbon for the same enzyme loading [101]. This is an interesting 
advantage which can be further applied for enzymatic anodes in BFCs. Moreover, porous carbon-based electrodes are also helpful for cathodic applications. For instance, an optimal composition of porous material (33\% macro- and 67\% mesopores) modified with BOD could provide an ORR current as high as $15 \mathrm{~mA} \mathrm{~cm}^{-2}$ [102]. It should be noted that in addition to the total quantity of the enzyme immobilized on the carbon, the mass transfer of $\mathrm{O}_{2}$ gas from the solution to the immobilized enzymes also determines the ORR process. Therefore, the pore size and architecture are important. For example, too high of a percentage of mesopores (in other words, a low percentage of macropores) will obstruct the mass transfer of the $\mathrm{O}_{2}$, causing an unwanted decrease in net efficiency.

Porous materials also offer unique architectures with favorably high specific surface areas and ion diffusion channels. These factors determine the performance of energy devices. Therefore, porous carbon allows for the fabrication of lightweight supercapacitors due to the small packing density and high gravimetric capacitance. Major developments of porous carbon materials have been made in supercapacitor technology. For instance, porous carbon-coated carbon fibers and copper hexacyanoferrate coated carbon fibers are used as negative and positive electrodes, respectively [103]. Such an asymmetric supercapacitor provides a high-voltage fiber-based energy-storage device (up to $2 \mathrm{~V}$ ). The carbon material possesses many pores and a large area (surface area of $1117 \mathrm{~m}^{2} \mathrm{~g}^{-1}$; pore size of $4 \mathrm{~nm}$; pore volume of $0.19 \mathrm{~cm}^{3} \mathrm{~g}^{-1}$ ). Note that the material consists of mesopores in the range of $\sim 2.6-2.8 \mathrm{~nm}, 2.9-3.1 \mathrm{~nm}$, and $\sim 3.5-4.5 \mathrm{~nm}$. The assembled carbon-based device exhibits a good specific capacitance of $19 \mathrm{~F} \mathrm{~g}^{-1}\left(68 \mathrm{mF} \mathrm{cm}{ }^{-2}\right.$ or $\left.3 \mathrm{~F} \mathrm{~cm}^{-3}\right)$ and an energy density of $11 \mathrm{~W} \mathrm{~h} \mathrm{~kg}^{-1}\left(181 \mu \mathrm{W} \mathrm{h} \mathrm{cm} \mathrm{cm}^{-2}\right.$ or $8 \mathrm{~mW} \mathrm{~h} \mathrm{~cm}^{-3}$ ) while maintaining flexibility.

\subsection{Mechanical Properties of Carbon-based Electrodes}

The achievement of practical personalized energy devices requires careful attention to crucial challenges pertaining to mechanical resilience. Traditional, bulky, and heavy energy devices limit practical wearable and implantable applications because they would not provide an intimate integration with the real human body. The devices would require curvilinear and mechanical resilience to daily life, capable of multiplexed movements and various strain distortions from constant use. Moreover, applying large deformations to non-stretchable devices can induce a severe deterioration of energy performances. Therefore, for practical bioapplications, materials used to fabricate new carbon-based energy devices should be tuned to match the mechanical properties of human tissues. Recently, soft, flexible, and stretchable energy devices have thus received great attention [104,105]. Carbon-based nanomaterials are also fascinating candidates because of their high specific surface area, good electrical conductivity, and outstanding thermal and chemical stability [106]. Such materials as CNTs, graphene, and their composites with different forms are the most commonly used nanomaterials in stretchable electrodes. The nanomaterials do not only serve as electro-active materials but can also be used to collect current in many flexible energy device systems. In order to address the mechanical challenges, compliant materials or specially engineered structures which show mechanical properties in a similar range of skin's modulus have been explored.

Graphene-CNT-layered structure was applied for all-solid-state stretchable supercapacitors [107]. The strong van der Waals interaction due to graphitic stacking between CNTs and graphene offers a stable carbon composite. Note that the energy required to move the CNT (as a motor) along the graphene track platform was as small as $0.08 \mathrm{eV} \mathrm{U} \mathrm{C}^{-1}$, smaller than the external stress. This suggested that external stress would not deform the graphene sheet. Hence, this graphene-CNT-layered assembly enabled omnidirectional resiliency, and allowed the development of all-solid-state, stretchable supercapacitors with a capacitance of $329 \mathrm{~F} \mathrm{~g}^{-1}$.

Furthermore, one strategy is employing polymers to blend with carbon materials because of the low mechanical toughness of polymers. Soft elastomers, such as PU and styrene-butadiene-styrene (SBS), can be integrated with CNTs, useful for electrochemical energy devices $[15,56,108]$. For instance, CNTs with the high-aspect-ratio of $\sim 1300$ could be used as a conductive filler to blend with the soft PU binder [15]. The carboxyl groups of the functionalized CNTs can provide good hydrogen bonds with 
PU, ensuring good dispersion and stability of stretchable CNT composite. In this case, the percolation of the well-distributed CNT filler facilitates current flow in stretchable energy devices. It should be noted that geometrical dimensions, concentration, and percolation are all critical parameters. CNTs are outstanding at generating percolation networks due to their excellent intrinsic conductivity and high aspect ratios $[109,110]$. In addition to the intrinsic stretchability of this carbon-elastomer composite, the additional structural stretchability (induced by the serpentine design) also helps the device to endure strains as high as $500 \%$ with an insignificant effect on its electrochemical performance [56]. Moreover, this concept can be expanded by adding extra desirable materials into electrodes. For example, $\mathrm{MnO}_{2}$ nanoplates and poly(3,4-ethylenedioxythiophene)-poly(styrenesulfonate) could be integrated with CNT-based materials to offer stretchable materials with enhanced pseudocapacitive properties for energy-storage applications [32]. Stretchable platinized carbon-based materials could also be prepared, suggesting possible applications in the future for electrocatalytic ORR electrodes [111]. Notably, the major advantage of elastomer-carbon composites is their capability to be applied as screen-printable inks that can be coated on a variety of substrates, such as clothes, socks, and temporary tattoos $[15,56]$.

In addition, another interesting property is the design of the structural stretchability, done by engineering wavy carbon architectures. For example, buckled CNT ribbons could be prepared by the following methods [112]. First, a thin Au/Pd film was sputtered onto the CNT ribbons (sheet resistance of $211 \Omega^{-1}$ ). Subsequently, the resulting noble metal-coated CNT ribbons were transferred onto a pre-stretched elastomeric film. Finally, the pre-strain was relaxed, which generated wavy out-of-plane buckling of the CNT ribbon. Such wavy CNT ribbons could withstand a strain of $100 \%$. Flexible and stretchable platforms of carbon-based electrodes enable many next-generation wearable or implantable energy applications, opening up several avenues for healthcare, energy, and sport purposes.

\section{Conclusions and Prospects}

Carbon-based energy devices in conformal and/or miniaturized platforms help facilitate a new style of personalized electronics that could open up attractive opportunities for a variety of applications, such as powering smart wearable or implantable devices, biosensors, bioelectronics, and personalized biomedical devices. These personalized energy-storage devices will invariably deliver optimal power to biomedical systems upon demand of an individual user and are necessary for integration with energy-harvesting and energy-converting devices. Additionally, carbon-based energy devices would serve to power biomedical devices, such as pacemakers, implantable radio transmitters, gastric stimulators, smart gesture gloves, fitness and motion trackers, and wearable biosensors.

Although many researchers have devoted more effort toward the development of personalized energy devices, there are still a number of challenges that need to be dealt with. Single and multi-walled CNTs, graphene, buckypaper, and other such carbon materials are of specific interest for implementation in personalized energy applications. However, as discussed in our article, limitations such as establishing efficient electron communication between carbon and enzyme, oxygen reduction optimization, enhancing enzyme stability, finding the ideal carbon material surface area, and tuning mechanical properties have continued to be major challenges in this field.

Moreover, personalized carbon-based energy devices that possess flexible, stretchable, or miniaturized platforms have typically shown a lower performance than structurally rigid or planar conventional devices. The mechanical resiliency of such carbon-based energy devices and personalized devices can also be difficult to deal with. For instance, biomedical energy storage devices need to be directly attached onto the body as a skin-patch or implanted in-vivo. Therefore, the materials and components that make up these biomedical devices must be able to withstand severe variations of mobility in human motion. Besides these aspects of mechanical robustness, dynamic biological environments must also be kept into account. By optimizing the structure and morphology of the active carbon materials being used, we expect further research to enhance the compatibility of personalized energy devices for real-world biological/biomedical applications. 
The effects of biofouling on carbon-based biodevices are another challenge to the development of energy biodevices for long-term use. The stability of these devices may become compromised, seeing as how they rely on their capacity to sustain their functionality when coming into contact with biofluids or human tissues. Fouling may also occur, creating a challenging impact. Such effects can suppress surface performance and reduce the surface area of carbon electrodes. This phenomenon must be addressed at all costs, especially for long-term in-vivo applications. Consequently, keen attention should be paid to applications in energy biodevices. When modifying the carbon electrode surfaces, one should optimize strategies to minimize biofouling at the membranes of the biodevice [113,114]. Approaches to move biodevices toward the use in complex biological systems should be considered $[45,51,115,116]$. Such energy biodevices have been investigated in various artificial solutions, real human sweat $[15,32,71,117]$, whole blood [116], and in-vivo implanted conditions with animal models [45,51]. Further interesting topics of research may be done to investigate the performance of such carbon-based biodevices throughout long-term exposure to biofoulants.

Further investigation would also seek to analyze the carbon nanomaterials in 3D structures. These structures are composed of a unique network of many interconnected pores. This composition allows the carbon structure to utilize more ion/charge and electrochemical pathways, possess larger surface areas, and overcome a collapse of carbon layers when being used in various bioapplications. Moreover, it is crucial to understand the surface chemistry that influences the electrochemical interactions in carbon materials. This is essential in nanostructuring to improve material and device performance, where the surface chemistry influence is decidedly greater.

Electrochemical capacitors can be fully charged in minutes, and in some cases seconds, ensuring fast energy storage. However, the capacitors may store 1-2 orders of magnitude less energy compared to conventional batteries. The development of new personalized carbon-based supercapacitor systems must be further explored, seeing as how self-discharging can lead to energy loss. Consequently, finding a way to minimize the self-discharging phenomenon on the carbon-based material surface should be prioritized. Similarly, electrolytes that are integrated with compliant carbon electrodes are of significant importance to energy storage, and should also be explored. Further studies should also be directed toward developing new electrolytes with high compatibility with carbon electrodes.

Bioharvesting energy devices, such as BFCs, can enhance their energy conversion efficiency by incorporating metal nanoparticles with high catalytic activity and synthesizing redox mediators onto carbon surfaces. The most favorable combination of carbon-based electrodes, comprised of carbon nanomaterials, are nanocomposites with either conductive polymers or nano metal oxides. This is due to their additional retention of high power and energy densities for use in energy-storage devices. As a result, future prospects would explore similar nanohybrid carbon composite structures necessary for controlling the interaction between carbon interfacing with pseudocapacitive nanomaterials, in order to advance Faradic processes across the interface. Another topic that serves of interest for further investigation is the role of heteroatoms within the functional groups attached to carbon nanomaterials. By researching the reactions involved with carbon-heteroatoms, one can further understand the necessary conditions for excellent electrochemical performance of modified carbon materials. Furthermore, the multifunctionalities of these self-powered hybrid systems have attracted considerable interest in the future development of incorporating highly flexible BFCs and supercapacitors with other energy devices, such as nano-generators.

Physical properties and features of the personalized energy devices should be given attention as well. The focus should also be placed on the stability of the wearable and implantable carbon-based energy devices for long term use. Materials which can self-heal are of considerable interest as a smart material capable of restoring some, if not all, of its functionality upon suffering external stress or mechanical damage. The physical property of adhesion should also be considered when fabricating devices with active conformal contact with the body or personal biological tissues. For instance, this should be considered by ensuring the adhesion energy is larger than the total energies of the substrate bending and elasticity of the biological tissue. 
With the onset development of personalized biomedical and information technologies, the demand for energy devices increases, further driving the development of integrated biodevices. These devices would possess features that include skin-patchable and implantable materials for new classes of personalized medical diagnosis, and prognosis, and therapeutic applications. BFCs have enormous potential as a power source in implantable and wearable biomedical systems, also including self-powered biosensors. The unique morphology of human skin and tissue can prove to be a challenge for interfacing with energy storage materials, along with the dynamic biological conditions of an in-vivo environment. New biomedical systems, in general, are in the internet of things (IoTs) and information and communications technology (ICT), advancing evolutionary stages where they can communicate with external systems and databases for real-time tracking, detection, diagnosis, and treatment. All applications require effective energy sources to support.

We envision that the field of personalized biomedical devices would greatly benefit from the development of carbon materials for individual energy devices. Some of the major impediments to the widespread adoption of carbon-based biodevices in commercial applications have been specifically addressed through new innovative approaches and advanced nanomaterials. These new carbon materials enable important new applications in the medical field and can improve the performance of such biomedical devices. With continuous innovations in material sciences and by addressing and engineering existing issues, carbon-based devices can reach their full potential as reliable, energy-efficient staples in the modern industry. We anticipate that personalized electronics will become important elements in daily life as an eventuality, despite challenges facing the energy devices so far. Their enormous potential in fields such as biosystem monitoring and diagnosing diseases would help advance the personalized healthcare field. They serve an important role in biomedical systems such as wearable sensing devices, pacemakers, insulin pumps, cochlear implanted devices, cardiac defibrillators, and gastric stimulators.

Another important issue to face is the need to develop a continuous fabrication process in order to scale up the production of high-performance carbon-based energy devices. These devices should be utilized for both industrial and commercial applications. Synthesizing of the carbon nanomaterials with the high throughput manufacturing processes of the devices must be developed on a larger scale. Through collaboration amongst material experts, electrochemists, biologists, and electronic engineers, personalized carbon-based energy technology can make a positive difference in a variety of personalized applications. Such "personalized devices" would be integrated with modern noninvasive, minimally invasive, wearable, or implanted bioelectronics to offer new opportunities in smart, personalized preventive medical care. With a seemingly endless supply of opportunities, the field of carbon-based energy devices (particularly, supercapacitors and BFCs) grows with potential and maintains an open-ended outlook, providing researchers of varying backgrounds the ability to explore new novel concepts and designs. We believe this field of devices can shift the current of modern energy storage capabilities emerging in the near future.

Conflicts of Interest: The authors declare no conflict of interest.

\section{References}

1. Obreja, V.V.N. Supercapacitors Based on Carbon Nanomaterials. In Carbon Nanomaterials for Advanced Energy System; John Wiley \& Sons, Inc.: Hoboken, NJ, USA, 2015; Volume 9, pp. 295-337. [CrossRef]

2. Dai, L.; Chang, D.W.; Baek, J.-B.; Lu, W. Carbon Nanomaterials for Advanced Energy Conversion and Storage. Small 2012, 8, 1130-1166. [CrossRef]

3. Bariya, M.; Nyein, H.Y.Y.; Javey, A. Wearable sweat sensors. Nat. Electron. 2018, 1, 160-171. [CrossRef]

4. Kim, J.; Jeerapan, I.; Sempionatto, J.R.; Barfidokht, A.; Mishra, R.K.; Campbell, A.S.; Hubble, L.J.; Wang, J. Wearable Bioelectronics: Enzyme-Based Body-Worn Electronic Devices. Acc. Chem. Res. 2018, 51, 2820-2828. [CrossRef] 
5. Cao, X.; Halder, A.; Tang, Y.; Hou, C.; Wang, H.; Duus, J.Ø.; Chi, Q. Engineering two-dimensional layered nanomaterials for wearable biomedical sensors and power devices. Mater. Chem. Front. 2018, 2, 1944-1986. [CrossRef]

6. Someya, T.; Bao, Z.; Malliaras, G.G. The rise of plastic bioelectronics. Nature 2016, 540, 379. [CrossRef]

7. Gao, B.; Wang, X.; Li, T.; Feng, Z.; Wang, C.; Gu, Z. Gecko-Inspired Paper Artificial Skin for Intimate Skin Contact and Multisensing. Adv. Mater. Technol. 2019, 4, 1800392. [CrossRef]

8. Cianchetti, M.; Laschi, C.; Menciassi, A.; Dario, P. Biomedical applications of soft robotics. Nat. Rev. Mater. 2018, 3, 143-153. [CrossRef]

9. Koydemir, H.C.; Ozcan, A. Wearable and Implantable Sensors for Biomedical Applications. Annu. Rev. Anal. Chem. 2018, 11, 127-146. [CrossRef]

10. Dubal, D.P.; Chodankar, N.R.; Kim, D.-H.; Gomez-Romero, P. Towards flexible solid-state supercapacitors for smart and wearable electronics. Chem. Soc. Rev. 2018, 47, 2065-2129. [CrossRef]

11. Liu, L.; Feng, Y.; Wu, W. Recent progress in printed flexible solid-state supercapacitors for portable and wearable energy storage. J. Power Sources 2019, 410-411, 69-77. [CrossRef]

12. Yun, J.; Song, C.; Lee, H.; Park, H.; Jeong, Y.R.; Kim, J.W.; Jin, S.W.; Oh, S.Y.; Sun, L.; Zi, G.; et al. Stretchable array of high-performance micro-supercapacitors charged with solar cells for wireless powering of an integrated strain sensor. Nano Energy 2018, 49, 644-654. [CrossRef]

13. Falk, M.; Shleev, S. Hybrid dual-functioning electrodes for combined ambient energy harvesting and charge storage: Towards self-powered systems. Biosens. Bioelectron. 2019, 126, 275-291. [CrossRef]

14. Jeerapan, I. Wearable Skin-Worn Enzyme-Based Electrochemical Devices: Biosensing, Energy Harvesting, and Self-Powered Sensing. In Wearable Devices; IntechOpen: London, UK, 2019. [CrossRef]

15. Jeerapan, I.; Sempionatto, J.R.; Pavinatto, A.; You, J.-M.; Wang, J. Stretchable biofuel cells as wearable textile-based self-powered sensors. J. Mater. Chem. A 2016, 4, 18342-18353. [CrossRef]

16. Xiao, X.; Siepenkoetter, T.; Conghaile, P.Ó.; Leech, D.; Magner, E. Nanoporous Gold-Based Biofuel Cells on Contact Lenses. ACS Appl. Mater. Interfaces 2018, 10, 7107-7116. [CrossRef]

17. Valdés-Ramírez, G.; Li, Y.-C.; Kim, J.; Jia, W.; Bandodkar, A.J.; Nuñez-Flores, R.; Miller, P.R.; Wu, S.-Y.; Narayan, R.; Windmiller, J.R.; et al. Microneedle-based self-powered glucose sensor. Electrochem. Commun. 2014, 47, 58-62. [CrossRef]

18. Güven, G.; Şahin, S.; Güven, A.; Yu, E.H. Power Harvesting from Human Serum in Buckypaper-Based Enzymatic Biofuel Cell. Front. Energy Res. 2016, 4. [CrossRef]

19. Eatemadi, A.; Daraee, H.; Karimkhanloo, H.; Kouhi, M.; Zarghami, N.; Akbarzadeh, A.; Abasi, M.; Hanifehpour, Y.; Joo, S.W. Carbon nanotubes: properties, synthesis, purification, and medical applications. Nanoscale Res. Lett. 2014, 9, 393. [CrossRef]

20. Tang, L.; Wang, Y.; Li, Y.; Feng, H.; Lu, J.; Li, J. Preparation, Structure, and Electrochemical Properties of Reduced Graphene Sheet Films. Adv. Funct. Mater. 2009, 19, 2782-2789. [CrossRef]

21. Tanaka, K.; Iijima, S. Carbon Nanotubes and Graphene; Elsevier (Newnes): Amsterdam, The Netherlands, 2014.

22. Sun, Y.-P.; Fu, K.; Lin, Y.; Huang, W. Functionalized Carbon Nanotubes: Properties and Applications. Acc. Chem. Res. 2002, 35, 1096-1104. [CrossRef]

23. Zhu, Y.; Murali, S.; Cai, W.; Li, X.; Suk, J.W.; Potts, J.R.; Ruoff, R.S. Graphene and Graphene Oxide: Synthesis, Properties, and Applications. Adv. Mater. 2010, 22, 3906-3924. [CrossRef]

24. Lemine, A.S.; Zagho, M.M.; Altahtamouni, T.M.; Bensalah, N. Graphene a promising electrode material for supercapacitors-A review. Int. J. Energy Res. 2018, 42, 4284-4300. [CrossRef]

25. Jewell, D.; Duong, H.; Cheng, H. Advanced Supercapacitors Using Carbon Nanotubes. Mater. Res. Found. 2017, 12, 207-228. [CrossRef]

26. Conway, B.E. Electrochemical Supercapacitors: Scientific Fundamentals and Technological Applications; Springer Science \& Business Media: Berlin, Germany, 2013.

27. Borenstein, A.; Hanna, O.; Attias, R.; Luski, S.; Brousse, T.; Aurbach, D. Carbon-based composite materials for supercapacitor electrodes: a review. J. Mater. Chem. C 2017, 5, 12653-12672. [CrossRef]

28. Raccichini, R.; Varzi, A.; Passerini, S.; Scrosati, B. The role of graphene for electrochemical energy storage. Nat. Mater. 2014, 14, 271. [CrossRef] [PubMed]

29. Meng, Q.; Cai, K.; Chen, Y.; Chen, L. Research progress on conducting polymer based supercapacitor electrode materials. Nano Energy 2017, 36, 268-285. [CrossRef] 
30. Rajendran, V.; Mohan, A.M.V.; Jayaraman, M.; Nakagawa, T. All-printed, interdigitated, freestanding serpentine interconnects based flexible solid state supercapacitor for self powered wearable electronics. Nano Energy 2019, 65, 104055. [CrossRef]

31. Daneshvar, F.; Aziz, A.; Abdelkader, A.M.; Zhang, T.; Sue, H.-J.; Welland, M.E. Porous SnO2-Cu x O nanocomposite thin film on carbon nanotubes as electrodes for high performance supercapacitors. Nanotechnology 2018, 30, 015401. [CrossRef]

32. Lv, J.; Jeerapan, I.; Tehrani, F.; Yin, L.; Silva-Lopez, C.A.; Jang, J.-H.; Joshuia, D.; Shah, R.; Liang, Y.; Xie, L.; et al. Sweat-based wearable energy harvesting-storage hybrid textile devices. Energy Environ. Sci. 2018, 11, 3431-3442. [CrossRef]

33. Feng, N.; Meng, R.; Zu, L.; Feng, Y.; Peng, C.; Huang, J.; Liu, G.; Chen, B.; Yang, J. A polymer-direct-intercalation strategy for MoS2/carbon-derived heteroaerogels with ultrahigh pseudocapacitance. Nat. Commun. 2019, 10, 1372. [CrossRef]

34. Jiang, D.; Liang, H.; Yang, W.; Liu, Y.; Cao, X.; Zhang, J.; Li, C.; Liu, J.; Gooding, J.J. Screen-printable films of graphene/CoS $2 / \mathrm{Ni}_{3} \mathrm{~S}_{4}$ composites for the fabrication of flexible and arbitrary-shaped all-solid-state hybrid supercapacitors. Carbon 2019, 146, 557-567. [CrossRef]

35. Gu, W.; Yushin, G. Review of nanostructured carbon materials for electrochemical capacitor applications: advantages and limitations of activated carbon, carbide-derived carbon, zeolite-templated carbon, carbon aerogels, carbon nanotubes, onion-like carbon, and graphene. Wiley Interdiscip. Rev. Energy Environ. 2014, 3, 424-473. [CrossRef]

36. Gao, S.; Wang, K.; Du, Z.; Wang, Y.; Yuan, A.; Lu, W.; Chen, L. High power density electric double-layer capacitor based on a porous multi-walled carbon nanotube microsphere as a local electrolyte micro-reservoir. Carbon 2015, 92, 254-261. [CrossRef]

37. Zhou, G.; Kim, N.-R.; Chun, S.-E.; Lee, W.; Um, M.-K.; Chou, T.-W.; Islam, M.F.; Byun, J.-H.; Oh, Y. Highly porous and easy shapeable poly-dopamine derived graphene-coated single walled carbon nanotube aerogels for stretchable wire-type supercapacitors. Carbon 2018, 130, 137-144. [CrossRef]

38. Brownson, D.A.C.; Kampouris, D.K.; Banks, C.E. An overview of graphene in energy production and storage applications. J. Power Source 2011, 196, 4873-4885. [CrossRef]

39. Xiong, G.; Meng, C.; Reifenberger, R.G.; Irazoqui, P.P.; Fisher, T.S. A Review of Graphene-Based Electrochemical Microsupercapacitors. Electroanalysis 2014, 26, 30-51. [CrossRef]

40. Stoner, B.R.; Raut, A.S.; Brown, B.; Parker, C.B.; Glass, J.T. Graphenated carbon nanotubes for enhanced electrochemical double layer capacitor performance. Appl. Phys. Lett. 2011, 99, 183104. [CrossRef]

41. Ling, Y.; Zhuang, X.; Xu, Z.; Xie, Y.; Zhu, X.; Xu, Y.; Sun, B.; Lin, J.; Zhang, Y.; Yan, Z. Mechanically Assembled, Three-Dimensional Hierarchical Structures of Cellular Graphene with Programmed Geometries and Outstanding Electromechanical Properties. ACS Nano 2018, 12, 12456-12463. [CrossRef]

42. Manjakkal, L.; Núñez, C.G.; Dang, W.; Dahiya, R. Flexible self-charging supercapacitor based on graphene-Ag-3D graphene foam electrodes. Nano Energy 2018, 51, 604-612. [CrossRef]

43. Xu, T.; Yang, D.; Fan, Z.; Li, X.; Liu, Y.; Guo, C.; Zhang, M.; Yu, Z.-Z. Reduced graphene oxide/carbon nanotube hybrid fibers with narrowly distributed mesopores for flexible supercapacitors with high volumetric capacitances and satisfactory durability. Carbon 2019, 152, 134-143. [CrossRef]

44. Han, J.; Wang, H.; Yue, Y.; Mei, C.; Chen, J.; Huang, C.; Wu, Q.; Xu, X. A self-healable and highly flexible supercapacitor integrated by dynamically cross-linked electro-conductive hydrogels based on nanocellulose-templated carbon nanotubes embedded in a viscoelastic polymer network. Carbon 2019, 149, 1-18. [CrossRef]

45. Sim, H.J.; Choi, C.; Lee, D.Y.; Kim, H.; Yun, J.-H.; Kim, J.M.; Kang, T.M.; Ovalle, R.; Baughman, R.H.; Kee, C.W.; et al. Biomolecule based fiber supercapacitor for implantable device. Nano Energy 2018, 47, 385-392. [CrossRef]

46. Xiao, X.; Xia, H.-q.; Wu, R.; Bai, L.; Yan, L.; Magner, E.; Cosnier, S.; Lojou, E.; Zhu, Z.; Liu, A. Tackling the Challenges of Enzymatic (Bio)Fuel Cells. Chem. Rev. 2019, 119, 9509-9558. [CrossRef] [PubMed]

47. Jeerapan, I.; Sempionatto, J.R.; Wang, J. On-Body Bioelectronics: Wearable Biofuel Cells for Bioenergy Harvesting and Self-Powered Biosensing. Adv. Funct. Mater. 2019. [CrossRef]

48. Grattieri, M.; Minteer, S.D. Self-Powered Biosensors. ACS Sens. 2018, 3, 44-53. [CrossRef]

49. Fu, L.; Liu, J.; Hu, Z.; Zhou, M. Recent Advances in the Construction of Biofuel Cells Based Self-powered Electrochemical Biosensors: A Review. Electroanalysis 2018, 30, 2535-2550. [CrossRef] 
50. Katz, E. Boolean Logic Gates Realized with Enzyme-catalyzed Reactions - Unusual Look at Usual Chemical Reactions. ChemPhysChem 2019, 20, 9-22. [CrossRef]

51. El Ichi-Ribault, S.; Alcaraz, J.-P.; Boucher, F.; Boutaud, B.; Dalmolin, R.; Boutonnat, J.; Cinquin, P.; Zebda, A.; Martin, D.K. Remote wireless control of an enzymatic biofuel cell implanted in a rabbit for 2 months. Electrochim. Acta 2018, 269, 360-366. [CrossRef]

52. Prasad, K.P.; Chen, Y.; Chen, P. Three-Dimensional Graphene-Carbon Nanotube Hybrid for High-Performance Enzymatic Biofuel Cells. ACS Appl. Mater. Interfaces 2014, 6, 3387-3393. [CrossRef]

53. Zhang, Y.; Chu, M.; Yang, L.; Tan, Y.; Deng, W.; Ma, M.; Su, X.; Xie, Q. Three-Dimensional Graphene Networks as a New Substrate for Immobilization of Laccase and Dopamine and Its Application in Glucose/O2 Biofuel Cell. ACS Appl. Mater. Interfaces 2014, 6, 12808-12814. [CrossRef]

54. Mazurenko, I.; Monsalve, K.; Rouhana, J.; Parent, P.; Laffon, C.; Goff, A.L.; Szunerits, S.; Boukherroub, R.; Giudici-Orticoni, M.-T.; Mano, N.; et al. How the Intricate Interactions between Carbon Nanotubes and Two Bilirubin Oxidases Control Direct and Mediated $\mathrm{O}_{2}$ Reduction. ACS Appl. Mater. Interfaces 2016, 8, 23074-23085. [CrossRef]

55. Campbell, A.S.; Jeong, Y.J.; Geier, S.M.; Koepsel, R.R.; Russell, A.J.; Islam, M.F. Membrane/Mediator-Free Rechargeable Enzymatic Biofuel Cell Utilizing Graphene/Single-Wall Carbon Nanotube Cogel Electrodes. ACS Appl. Mater. Interfaces 2015, 7, 4056-4065. [CrossRef] [PubMed]

56. Bandodkar, A.J.; Jeerapan, I.; You, J.-M.; Nuñez-Flores, R.; Wang, J. Highly Stretchable Fully-Printed CNT-Based Electrochemical Sensors and Biofuel Cells: Combining Intrinsic and Design-Induced Stretchability. Nano Lett. 2016, 16, 721-727. [CrossRef]

57. Sim, H.J.; Lee, D.Y.; Kim, H.; Choi, Y.-B.; Kim, H.-H.; Baughman, R.H.; Kim, S.J. Stretchable Fiber Biofuel Cell by Rewrapping Multiwalled Carbon Nanotube Sheets. Nano Lett. 2018, 18, 5272-5278. [CrossRef] [PubMed]

58. Niiyama, A.; Murata, K.; Shigemori, Y.; Zebda, A.; Tsujimura, S. High-performance enzymatic biofuel cell based on flexible carbon cloth modified with MgO-templated porous carbon. J. Power Source 2019, 427, $49-55$. [CrossRef]

59. Agnès, C.; Holzinger, M.; Le Goff, A.; Reuillard, B.; Elouarzaki, K.; Tingry, S.; Cosnier, S. Supercapacitor/biofuel cell hybrids based on wired enzymes on carbon nanotube matrices: autonomous reloading after high power pulses in neutral buffered glucose solutions. Energy Environ. Sci. 2014, 7, 1884-1888. [CrossRef]

60. Liu, Y.; Zhang, J.; Cheng, Y.; Jiang, S.P. Effect of Carbon Nanotubes on Direct Electron Transfer and Electrocatalytic Activity of Immobilized Glucose Oxidase. ACS Omega 2018, 3, 667-676. [CrossRef] [PubMed]

61. Lv, T.; Chen, T. Chapter 15-Carbon Nanotube and Graphene Fibers for Wearable Fiber-Shaped Energy Conversion. In Nanotube Superfiber Materials (Second Edition); Schulz, M.J., Shanov, V., Yin, Z., Cahay, M., Eds.; William Andrew Publishing: Norwich, NY, USA, 2019; pp. 359-381. [CrossRef]

62. Tsujimura, S.; Murata, K. Electrochemical Oxygen Reduction Catalyzed by Bilirubin Oxidase with the Aid of 2,2'-Azinobis(3-ethylbenzothiazolin-6-sulfonate) on a MgO-template Carbon Electrode. Electrochim. Acta 2015, 180, 555-559. [CrossRef]

63. Morishita, T.; Tsumura, T.; Toyoda, M.; Przepiórski, J.; Morawski, A.W.; Konno, H.; Inagaki, M. A review of the control of pore structure in MgO-templated nanoporous carbons. Carbon 2010, 48, 2690-2707. [CrossRef]

64. Tsujimura, S.; Oyama, M.; Funabashi, H.; Ishii, S. Effects of pore size and surface properties of MgO-templated carbon on the performance of bilirubin oxidase-modified oxygen reduction reaction cathode. Electrochim. Acta 2019, 322, 134744. [CrossRef]

65. Yeknami, A.F.; Wang, X.; Jeerapan, I.; Imani, S.; Nikoofard, A.; Wang, J.; Mercier, P.P. A 0.3-V CMOS Biofuel-Cell-Powered Wireless Glucose/Lactate Biosensing System. IEEE J. Solid-State Circuits 2018, 53, 3126-3139. [CrossRef]

66. Jang, Y.; Kim, S.M.; Spinks, G.M.; Kim, S.J. Carbon Nanotube Yarn for Fiber-Shaped Electrical Sensors, Actuators, and Energy Storage for Smart Systems. Adv. Mater. 2019, 1902670. [CrossRef]

67. Slaughter, G.; Kulkarni, T. Highly Selective and Sensitive Self-Powered Glucose Sensor Based on Capacitor Circuit. Sci. Rep. 2017, 7, 1471. [CrossRef]

68. Yuen, J.D.; Baingane, A.; Hasan, Q.; Shriver-Lake, L.C.; Walper, S.A.; Zabetakis, D.; Breger, J.C.; Stenger, D.A.; Slaughter, G. A Fully-Flexible Solution-Processed Autonomous Glucose Indicator. Sci. Rep. 2019, 9, 6931. [CrossRef] 
69. Shitanda, I.; Fujimura, Y.; Nohara, S.; Hoshi, Y.; Itagaki, M.; Tsujimura, S. Paper-Based Disk-Type Self-Powered Glucose Biosensor Based on Screen-Printed Biofuel Cell Array. J. Electrochem. Soc. 2019, 166, B1063-B1068. [CrossRef]

70. Gross, A.J.; Holzinger, M.; Cosnier, S. Buckypaper bioelectrodes: emerging materials for implantable and wearable biofuel cells. Energy Environ. Sci. 2018, 11, 1670-1687. [CrossRef]

71. Chen, X.; Yin, L.; Lv, J.; Gross, A.J.; Le, M.; Gutierrez, N.G.; Li, Y.; Jeerapan, I.; Giroud, F.; Berezovska, A.; et al. Stretchable and Flexible Buckypaper-Based Lactate Biofuel Cell for Wearable Electronics. Adv. Funct. Mater. 2019, 1905785. [CrossRef]

72. Heller, A. Electrical wiring of redox enzymes. Acc. Chem. Res. 1990, 23, 128-134. [CrossRef]

73. Conzuelo, F.; Marković, N.; Ruff, A.; Schuhmann, W. The Open Circuit Voltage in Biofuel Cells: Nernstian Shift in Pseudocapacitive Electrodes. Angew. Chem. Int. Ed. 2018, 57, 13681-13685. [CrossRef]

74. Luong, J.H.T.; Glennon, J.D.; Gedanken, A.; Vashist, S.K. Achievement and assessment of direct electron transfer of glucose oxidase in electrochemical biosensing using carbon nanotubes, graphene, and their nanocomposites. Microchimica Acta 2017, 184, 369-388. [CrossRef]

75. Wooten, M.; Karra, S.; Zhang, M.; Gorski, W. On the Direct Electron Transfer, Sensing, and Enzyme Activity in the Glucose Oxidase/Carbon Nanotubes System. Anal. Chem. 2014, 86, 752-757. [CrossRef]

76. Willner, I.; Yan, Y.-M.; Willner, B.; Tel-Vered, R. Integrated Enzyme-Based Biofuel Cells-A Review. Fuel Cells 2009, 9, 7-24. [CrossRef]

77. Yoshino, S.; Miyake, T.; Yamada, T.; Hata, K.; Nishizawa, M. Molecularly Ordered Bioelectrocatalytic Composite Inside a Film of Aligned Carbon Nanotubes. Adv. Energy Mater. 2013, 3, 60-64. [CrossRef]

78. Leech, D.; Kavanagh, P.; Schuhmann, W. Enzymatic fuel cells: Recent progress. Electrochim. Acta 2012, 84, 223-234. [CrossRef]

79. Rasmussen, M.; Abdellaoui, S.; Minteer, S.D. Enzymatic biofuel cells: 30 years of critical advancements. Biosens. Bioelectron. 2016, 76, 91-102. [CrossRef]

80. Reuillard, B.; Le Goff, A.; Agnes, C.; Holzinger, M.; Zebda, A.; Gondran, C.; Elouarzaki, K.; Cosnier, S. High power enzymatic biofuel cell based on naphthoquinone-mediated oxidation of glucose by glucose oxidase in a carbon nanotube 3D matrix. Phys. Chem. Chem. Phys. 2013, 15, 4892-4896. [CrossRef]

81. Jeerapan, I.; Ciui, B.; Martin, I.; Cristea, C.; Sandulescu, R.; Wang, J. Fully edible biofuel cells. J. Mater. Chem. B 2018, 6, 3571-3578. [CrossRef]

82. De Poulpiquet, A.; Ciaccafava, A.; Lojou, E. New trends in enzyme immobilization at nanostructured interfaces for efficient electrocatalysis in biofuel cells. Electrochim. Acta 2014, 126, 104-114. [CrossRef]

83. Holzinger, M.; Le Goff, A.; Cosnier, S. Carbon nanotube/enzyme biofuel cells. Electrochim. Acta 2012, 82, 179-190. [CrossRef]

84. Bartlett, P.N.; Al-Lolage, F.A. There is no evidence to support literature claims of direct electron transfer (DET) for native glucose oxidase (GOx) at carbon nanotubes or graphene. J. Electroanal. Chem. 2018, 819, 26-37. [CrossRef]

85. Lee, Y.S.; Baek, S.; Lee, H.; Reginald, S.S.; Kim, Y.; Kang, H.; Choi, I.-G.; Chang, I.S. Construction of Uniform Monolayer- and Orientation-Tunable Enzyme Electrode by a Synthetic Glucose Dehydrogenase without Electron-Transfer Subunit via Optimized Site-Specific Gold-Binding Peptide Capable of Direct Electron Transfer. ACS Appl. Mater. Interfaces 2018, 10, 28615-28626. [CrossRef]

86. Yeager, E. Electrocatalysts for $\mathrm{O} 2$ reduction. Electrochim. Acta 1984, 29, 1527-1537. [CrossRef]

87. Barton, S.C.; Kim, H.-H.; Binyamin, G.; Zhang, Y.; Heller, A. The "Wired" Laccase Cathode: High Current Density Electroreduction of $\mathrm{O} 2$ to Water at $+0.7 \mathrm{~V}$ (NHE) at pH 5. J. Am. Chem. Soc. 2001, 123, 5802-5803. [CrossRef] [PubMed]

88. Deng, S.; Jian, G.; Lei, J.; Hu, Z.; Ju, H. A glucose biosensor based on direct electrochemistry of glucose oxidase immobilized on nitrogen-doped carbon nanotubes. Biosens. Bioelectron. 2009, 25, 373-377. [CrossRef] [PubMed]

89. Gong, K.; Du, F.; Xia, Z.; Durstock, M.; Dai, L. Nitrogen-Doped Carbon Nanotube Arrays with High Electrocatalytic Activity for Oxygen Reduction. Science 2009, 323, 760. [CrossRef]

90. Xing, W.; Yin, M.; Lv, Q.; Hu, Y.; Liu, C.; Zhang, J. 1-Oxygen Solubility, Diffusion Coefficient, and Solution Viscosity. In Rotating Electrode Methods and Oxygen Reduction Electrocatalysts; Xing, W., Yin, G., Zhang, J., Eds.; Elsevier: Amsterdam, The Netherlands, 2014; pp. 1-31. [CrossRef] 
91. Yu, Y.; Xu, M.; Bai, L.; Han, L.; Dong, S. Recoverable hybrid enzymatic biofuel cell with molecular oxygen-independence. Biosens. Bioelectron. 2016, 75, 23-27. [CrossRef]

92. Jeerapan, I.; Sempionatto, J.R.; You, J.-M.; Wang, J. Enzymatic glucose/oxygen biofuel cells: Use of oxygen-rich cathodes for operation under severe oxygen-deficit conditions. Biosens. Bioelectron. 2018, 122, 284-289. [CrossRef]

93. Kontani, R.; Tsujimura, S.; Kano, K. Air diffusion biocathode with CueO as electrocatalyst adsorbed on carbon particle-modified electrodes. Bioelectrochemistry 2009, 76, 10-13. [CrossRef]

94. Rocchitta, G.; Spanu, A.; Babudieri, S.; Latte, G.; Madeddu, G.; Galleri, G.; Nuvoli, S.; Bagella, P.; Demartis, M.; Fiore, V.; et al. Enzyme Biosensors for Biomedical Applications: Strategies for Safeguarding Analytical Performances in Biological Fluids. Sensors 2016, 16, 780. [CrossRef]

95. Wang, J.; Liu, J.; Cepra, G. Thermal Stabilization of Enzymes Immobilized within Carbon Paste Electrodes. Anal. Chem. 1997, 69, 3124-3127. [CrossRef]

96. Wang, J.; Musameh, M.; Mo, J.-W. Acid Stability of Carbon Paste Enzyme Electrodes. Anal. Chem. 2006, 78, 7044-7047. [CrossRef]

97. Sotiropoulou, S.; Vamvakaki, V.; Chaniotakis, N.A. Stabilization of enzymes in nanoporous materials for biosensor applications. Biosens. Bioelectron. 2005, 20, 1674-1679. [CrossRef] [PubMed]

98. Simon, P.; Gogotsi, Y. Materials for electrochemical capacitors. Nat. Mater. 2008, 7, 845. [CrossRef] [PubMed]

99. Pierotti, R.; Rouquerol, J. Reporting physisorption data for gas/solid systems with special reference to the determination of surface area and porosity. Pure Appl. Chem 1985, 57, 603-619.

100. Mazurenko, I.; de Poulpiquet, A.; Lojou, E. Recent developments in high surface area bioelectrodes for enzymatic fuel cells. Curr. Opin. Electrochem. 2017, 5, 74-84. [CrossRef]

101. Flexer, V.; Brun, N.; Backov, R.; Mano, N. Designing highly efficient enzyme-based carbonaceous foams electrodes for biofuel cells. Energy Environ. Sci. 2010, 3, 1302-1306. [CrossRef]

102. Funabashi, H.; Takeuchi, S.; Tsujimura, S. Hierarchical meso/macro-porous carbon fabricated from dual MgO templates for direct electron transfer enzymatic electrodes. Sci. Rep. 2017, 7, 45147. [CrossRef]

103. Senthilkumar, S.T.; Kim, J.; Wang, Y.; Huang, H.; Kim, Y. Flexible and wearable fiber shaped high voltage supercapacitors based on copper hexacyanoferrate and porous carbon coated carbon fiber electrodes. $J$. Mater. Chem. C 2016, 4, 4934-4940. [CrossRef]

104. Yu, J.; Lu, W.; Pei, S.; Gong, K.; Wang, L.; Meng, L.; Huang, Y.; Smith, J.P.; Booksh, K.S.; Li, Q.; et al. Omnidirectionally Stretchable High-Performance Supercapacitor Based on Isotropic Buckled Carbon Nanotube Films. ACS Nano 2016, 10, 5204-5211. [CrossRef]

105. Choi, S.; Lee, H.; Ghaffari, R.; Hyeon, T.; Kim, D.-H. Recent Advances in Flexible and Stretchable Bio-Electronic Devices Integrated with Nanomaterials. Adv. Mater. 2016, 28, 4203-4218. [CrossRef]

106. Wang, C.; Xia, K.; Wang, H.; Liang, X.; Yin, Z.; Zhang, Y. Advanced Carbon for Flexible and Wearable Electronics. Adv. Mater. 2019, 31, 1801072. [CrossRef]

107. Nam, I.; Bae, S.; Park, S.; Yoo, Y.G.; Lee, J.M.; Han, J.W.; Yi, J. Omnidirectionally stretchable, high performance supercapacitors based on a graphene-carbon-nanotube layered structure. Nano Energy 2015, 15, 33-42. [CrossRef]

108. Laoui, T. Mechanical and Thermal Properties of Styrene Butadiene Rubber - Functionalized Carbon Nanotubes Nanocomposites. Fuller. Nanotubes Carbon Nanostruct. 2013, 21, 89-101. [CrossRef]

109. Kyrylyuk, A.V.; Hermant, M.C.; Schilling, T.; Klumperman, B.; Koning, C.E.; van der Schoot, P. Controlling electrical percolation in multicomponent carbon nanotube dispersions. Nat. Nanotechnol. 2011, 6, 364. [CrossRef] [PubMed]

110. Cohen, D.J.; Mitra, D.; Peterson, K.; Maharbiz, M.M. A Highly Elastic, Capacitive Strain Gauge Based on Percolating Nanotube Networks. Nano Lett. 2012, 12, 1821-1825. [CrossRef] [PubMed]

111. Abellán-Llobregat, A.; Jeerapan, I.; Bandodkar, A.; Vidal, L.; Canals, A.; Wang, J.; Morallón, E. A stretchable and screen-printed electrochemical sensor for glucose determination in human perspiration. Biosens. Bioelectron. 2017, 91, 885-891. [CrossRef] [PubMed]

112. Xu, F.; Wang, X.; Zhu, Y.; Zhu, Y. Wavy Ribbons of Carbon Nanotubes for Stretchable Conductors. Adv. Funct. Mater. 2012, 22, 1279-1283. [CrossRef]

113. Wisniewski, N.; Reichert, M. Methods for reducing biosensor membrane biofouling. Colloids Surf. B Biointerfaces 2000, 18, 197-219. [CrossRef] 
114. Barfidokht, A.; Gooding, J.J. Approaches Toward Allowing Electroanalytical Devices to be Used in Biological Fluids. Electroanalysis 2014, 26, 1182-1196. [CrossRef]

115. Wang, B.; Yang, P.; Ding, Y.; Qi, H.; Gao, Q.; Zhang, C. Improvement of the Biocompatibility and Potential Stability of Chronically Implanted Electrodes Incorporating Coating Cell Membranes. ACS Appl. Mater. Interfaces 2019, 11, 8807-8817. [CrossRef]

116. Cadet, M.; Gounel, S.; Stines-Chaumeil, C.; Brilland, X.; Rouhana, J.; Louerat, F.; Mano, N. An enzymatic glucose/O2 biofuel cell operating in human blood. Biosens. Bioelectron. 2016, 83, 60-67. [CrossRef]

117. Escalona-Villalpando, R.A.; Ortiz-Ortega, E.; Bocanegra-Ugalde, J.P.; Minteer, S.D.; Ledesma-García, J.; Arriaga, L.G. Clean energy from human sweat using an enzymatic patch. J. Power Sources 2019, 412, 496-504. [CrossRef]

(C) 2019 by the authors. Licensee MDPI, Basel, Switzerland. This article is an open access article distributed under the terms and conditions of the Creative Commons Attribution (CC BY) license (http://creativecommons.org/licenses/by/4.0/). 